\title{
Environmental applications using graphene composites: water remediation and gas adsorption
}

\author{
K. Christian Kemp, † Humaira Seema, † Muhammad Saleh, Nhien H. Le, \\ Kandula Mahesh, Vimlesh Chandra and Kwang S. Kim*
}

Received 19th November 2012

Accepted 17th February 2013

DOI: $10.1039 /$ c3nr33708a

www.rsc.org/nanoscale

\begin{abstract}
This review deals with wide-ranging environmental studies of graphene-based materials on the adsorption of hazardous materials and photocatalytic degradation of pollutants for water remediation and the physisorption, chemisorption, reactive adsorption, and separation for gas storage. The environmental and biological toxicity of graphene, which is an important issue if graphene composites are to be applied in environmental remediation, is also addressed.
\end{abstract}

\section{Introduction}

Environmental pollution by both water soluble toxic pollutants as well as noxious greenhouse gases is causing great concern worldwide. At the recent Rio+20 conference, these issues have been thrust into the spotlight again, especially since most goals set during the initial Rio summit have not been met. ${ }^{1}$ Additionally, recent studies have shown that another issue affecting environmental stability is the unpredicted effects certain pollutants are having on the environment. ${ }^{2,3}$ It is for this reason that there has been a great interest in the development of new adsorbents for pollution management.

Graphene, the aptly named wonder material, has created a great deal of interest in academic and commercial circles since its isolation and characterization by Geim and Novoselov in 2004. ${ }^{4}$ This discovery eventually led to the pair sharing the Nobel Prize in physics in 2010, and a boom in the amount of

Center for Superfunctional Materials, Department of Chemistry, Pohang University of Science and Technology, Pohang 790-784, Korea.E-mail: kim@postech.ac.kr

$\dagger$ These authors contributed equally and are co-first authors. research articles concerning graphene. ${ }^{5}$ With potential applications ranging from electrocatalysis, ${ }^{6}$ DNA sensing, ${ }^{7}$ high resolution electron microscopy, ${ }^{8}$ electronics, ${ }^{9,10}$ flexible electronics, $^{11,12}$ bio culturing ${ }^{13}$ to desalination ${ }^{14}$ among many others, there seems to be no end in sight for graphene research. There have been multiple reviews on the structure/ chemistry and use of graphene published recently, however none of these reviews deal specifically with environmental concerns..$^{15-21}$

In this review we aim to show how graphene and its derivatives are being applied in pollution management with an emphasis on gas adsorption and water remediation. Section 2 will review the recent literature on the use of graphene in water remediation; due to the multiple studies in this field we have decided to split this section into 2 parts namely adsorption and photocatalytic. In Section 3, the focus of the review moves to the use of graphene in gas adsorption. In this section we deal with the physisorption and chemisorption of gases onto graphenebased materials. In Section 4 we deal with the toxicity of graphene, which is an important issue if graphene composites are to be applied in environmental remediation.

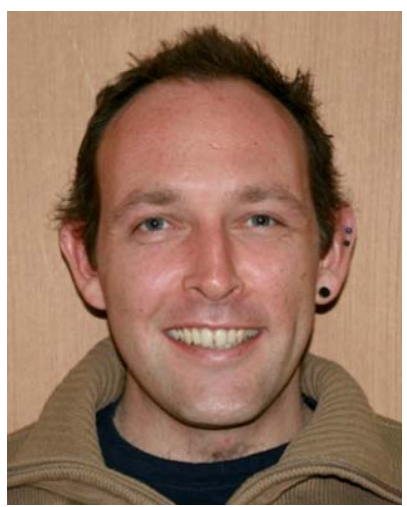

K. Christian Kemp received his MSc in chemistry from the University of the Free State, South Africa. He is currently pursuing a PhD at the Department of Chemistry, Pohang University of Science and Technology, under the guidance of Professor Kwang S. Kim.

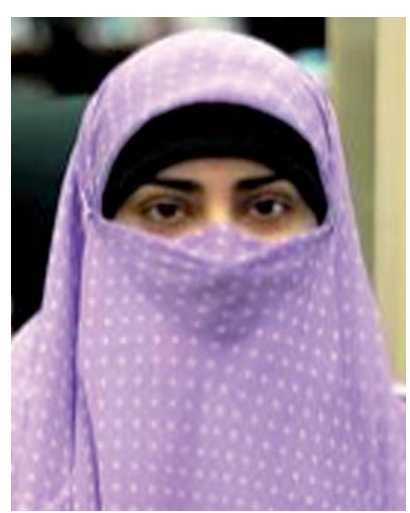

Humaira Seema (member of $59^{\text {th }}$ Meeting of Nobel Laureates dedicated for Chemistry held at Lindau, Germany) received her $\mathrm{MSc}$ in Chemistry from the University of Peshawar, Pakistan. She is currently pursuing a PhD at the Department of Chemistry, POSTECH, under the guidance of Professor Kwang S. Kim. 


\section{Water remediation}

\subsection{Water remediation by adsorption}

Water can be purified in multiple ways $^{22}$ i.e. desalination, ${ }^{\mathbf{1 4}}$ filtration, osmosis, adsorption, disinfection and sedimentation, however, adsorption holds many advantages over other methods. ${ }^{23}$ Adsorption is the surface phenomenon where pollutants are adsorbed on the surface of an adsorbent via physical forces. Adsorption depends on many factors such as temperature, $\mathrm{pH}$, concentration of pollutants, contact time, particle size, temperature, and nature of the adsorbate and adsorbent. ${ }^{24}$ Carbon-based materials such as activated carbon and carbon nanotubes have been used for water purification. ${ }^{25,26}$ The large scale production of functionalized graphene at low cost should result in good adsorbents for water purification. This is due to the two-dimensional layer structure, large surface area, pore volume and presence of surface functional groups in these materials. ${ }^{27-31}$ The inorganic nanoparticles present in 2D graphene nanocomposites prevent graphene aggregation, as such a high surface area and pore volume can be maintained. 3D reduced graphene oxide (rGO) composite materials have also been employed as adsorbents for water purification; these materials have been shown to be effective in the removal of dyes as well as other organic contaminants..$^{32-35}$

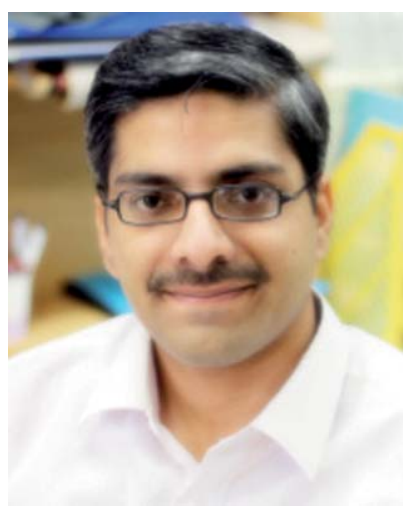

Muhammad Saleh received his MS degree from Pakistan Institute of Engineering and Applied Sciences (PIEAS), Pakistan. He currently works as a PhD student at the Department of Chemistry, Pohang University of Science and Technology with Professor Kwang S. Kim. His research interest is synthesis of materials for gas adsorption.

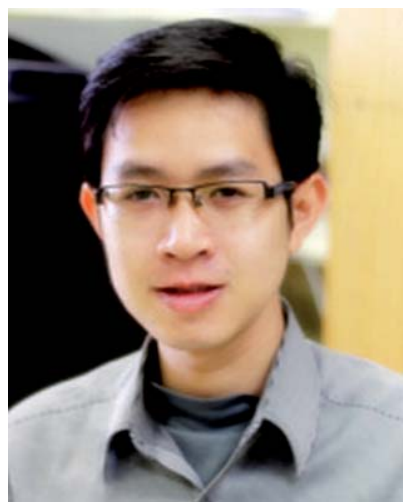

Nhien $H$. Le is a graduate student in the group of Professor Kwang S. Kim at the Department of Chemistry, Pohang University of Science and Technology. He received a $B S$ degree from Can Tho University, Vietnam, with his thesis on fabrication of biodegradable nanocomposites.
2.1.1 Adsorption of ionic pollutants. Ionic pollutants exist in polluted water in mainly two forms (i) metal ions such as arsenic, mercury, cadmium, chromium, cobalt, copper, selenium, lead and (ii) nonmetal ions such as fluoride, phosphate, nitrate, and sulphide. Nanomaterials (1-100 nm) are excellent pollutant adsorbents due to their small size, large surface area, high catalytic nature and multiple active sites. Bare nanoparticles result in agglomeration due to a high surface free energy which reduces the active adsorption sites. Graphene is highly stable, large in size ( $\mu \mathrm{m}$ to inch) and has a large surface area. To avoid aggregate formation of bare nanoparticles, graphene has been used as a supporting material in multiple studies. $^{15-21}$

The first use of functionalized graphene as an ionic water remediation adsorbent was conducted by Chandra et al. who showed that arsenic could be removed easily from contaminated water. ${ }^{36}$ Arsenic which exists in water as arsenite and arsenate ions is one of the most toxic and carcinogenic chemical elements when consumed in quantities above 10 parts per billion. In this study a water dispersible magnetite $\mathrm{Fe}_{3} \mathrm{O}_{4}-\mathrm{rGO}$ composite was synthesized by the simultaneous reduction of $\mathrm{GO}, \mathrm{FeCl}_{2}$ and $\mathrm{FeCl}_{3}$. The composite showed the formation of $10 \mathrm{~nm}$ magnetite nanoparticles on the rGO sheets, as well as a superparamagnetic nature at room temperature. The composite material showed a high binding capacity for As(III) and As(v)

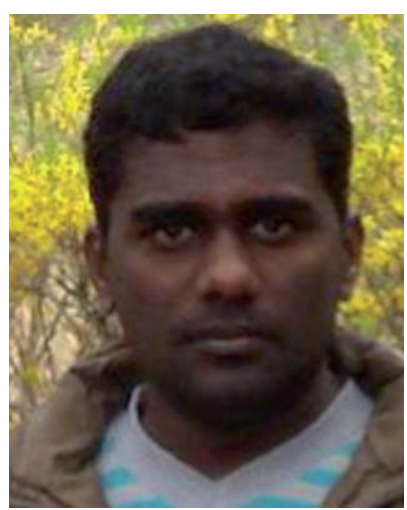

Kandula Mahesh received his MSc in chemistry from IIT Madras, India. He worked as a Research Assistant in IIT Bombay, India. He is currently pursuing a PhD at the Department of Chemistry, Pohang University of Science and Technology under the guidance of Professor Kwang S. Kim.

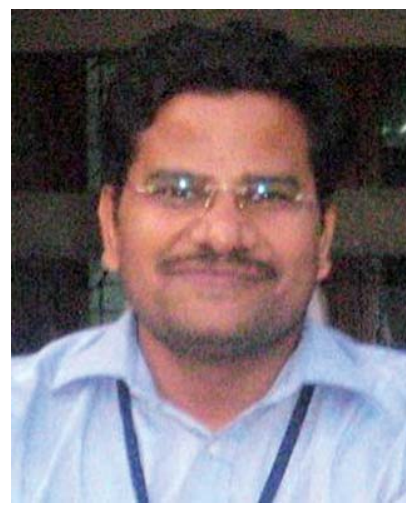

Vimlesh Chandra studied Natural Sciences at Lucknow University and received his $P h D$ degree from Indian Institute of Technology, Kanpur (2009). He has been a postdoctoral research fellow at the Center for Superfunctional Materials in the Department of Chemistry at Pohang University of Science and Technology since January 2009. He is developing graphene functionalized materials for water treatment and $\mathrm{CO}_{2}$ capturing. 
(99.9\% arsenic removal). Due to the intrinsic nature of this material it can be easily magnetically separated from purified water (see Fig. 1).

Zhang and colleagues have shown that arsenate removal with a maximum efficiency above 95\% over the 4-7 $\mathrm{pH}$ range can be achieved using a cross-linked ferric hydroxide-GO composite. $^{37}$ The cross linkage between the graphene sheets was obtained by the in situ oxidation of ferrous sulfate using hydrogen peroxide. Recently, Zhu et al. have developed graphene decorated with core-shell $\mathrm{Fe}-\mathrm{Fe}_{2} \mathrm{O}_{3}$ nanoparticles which show efficient adsorption capacity for As(III) in polluted water. ${ }^{38}$ This method takes advantage of the use of $\mathrm{Fe}_{2} \mathrm{O}_{3}$ which increases the total adsorption sites, while the Fe core makes the material magnetically separable. Luo and co-workers expanded further on this work, by showing that the introduction of $\mathrm{MnO}_{2}$ nanoparticles into a $\mathrm{Fe}_{3} \mathrm{O}_{4}$-rGO material increases the $\mathrm{pH}$ range of effective $\mathrm{As}(\mathrm{III})$ and $\mathrm{As}(\mathrm{v})$ adsorption. ${ }^{39}$ This material shows promise for application as $\mathrm{MnO}_{2}$ acts as an oxidant for As(III) without the need for addition of other oxidants for effective adsorption of $\operatorname{As}(\mathrm{v})$.

Since the initial report using magnetic iron containing graphene for water remediation, there have been multiple reports using various magnetic graphene composites. ${ }^{36}$ Humera et al. reported that iron decorated graphene sheets can be used for the removal of $\mathrm{Cr}(\mathrm{vI})$ from water through the catalytic reduction

(a)

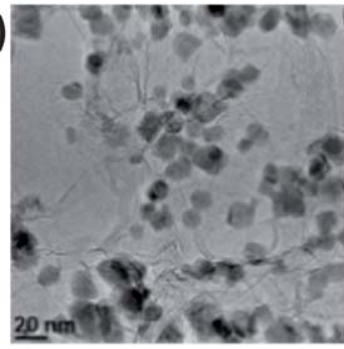

(b)

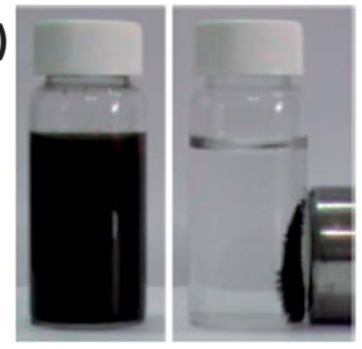

Fig. 1 (a) TEM image of the $\left(\mathrm{Fe}_{3} \mathrm{O}_{4}\right)-r G O$ composite and (b) magnetic separation of the composite from solution. Adapted with permission from V. Chandra, J. Park, Y. Chun, J. W. Lee, I.-C. Hwang and K. S. Kim, ACS Nano, 2010, 4, 3979. Copyright 2010 American Chemical Society.

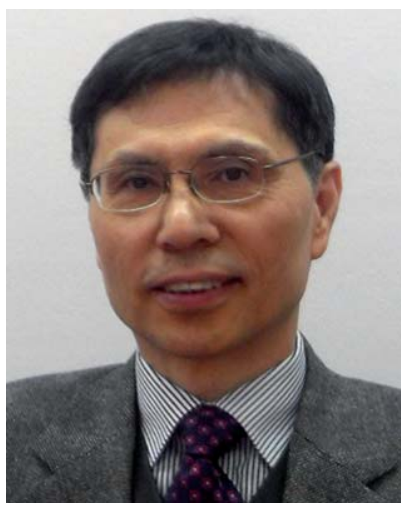

Kwang S. Kim received his $P h D$ degree from the University of California, Berkeley. He was a postdoctoral fellow at IBM and a visiting professor or scientist at Rutgers University, MIT, and Columbia University. Currently, he is a professor in the Department of Chemistry and the director of the Center for Superfunctional Materials at Pohang University of Science and Technology. His research interests include design and development of novel nanomaterials and molecular devices. of $\mathrm{Cr}(\mathrm{VI})$ to $\mathrm{Cr}(\mathrm{III}){ }^{40}$ Zhu et al. synthesized graphene decorated with core@double-shell nanoparticles, where the core is crystalline iron, the outer shell iron oxide and the external shell amorphous $\mathrm{Si}-\mathrm{S}-\mathrm{O}$. The material exhibited almost complete removal of $\mathrm{Cr}(\mathrm{vI})$ from wastewater within $5 \mathrm{~min}$ and could be separated from solution using an external magnetic field. ${ }^{41}$ As these studies using magnetic graphene have shown, there is a great potential for these types of materials as they can be modified to introduce other properties which enhance adsorption capacity. Additionally, many of these materials can be applied to absorb multiple pollutants i.e. organic and inorganic.

Cong et al. reported the metal ion induced self-assembly of $\alpha$-FeOOH-rGO hydrogels by the $\mathrm{NH}_{4} \mathrm{OH}$ reduction of $\mathrm{FeSO}_{4}$ and GO. The composite was shown to be effective in the removal of gasoline, $\mathrm{Cr}(\mathrm{VI})$ and $\mathrm{Pb}(\mathrm{II})$ from polluted water. ${ }^{42}$ Sreeprasad et al. synthesized $\mathrm{rGO}-\mathrm{metal} / \mathrm{metal}$ oxide composites using a redox-like reaction between GO and the metal precursors. ${ }^{27}$ They reported that the model compounds $\mathrm{Ag}-\mathrm{rGO}$ and $\mathrm{MnO}_{2}-$ rGO, which were either supported or unsupported on river sand, were highly effective in the removal of $\mathrm{Hg}$ (II) from water. Recently, Lee and Yang have shown that $\mathrm{TiO}_{2}$ decorated on GO can be used in the effective removal of the heavy metal cations $\mathrm{Zn}(\mathrm{II}), \mathrm{Cd}(\mathrm{II})$ and $\mathrm{Pb}(\mathrm{II}) .^{43}$

Another method that can be used to increase the adsorption capacity of graphene is functionalization with organic functionalities. ${ }^{17}$ Polymers which contain heteroatoms such as polypyrrole, polythiophene, and polyfuran have a strong affinity towards cations. This affinity is due to the electrostatic interaction between the lone pair of the heteroatom and the positively charged ions. These polymers would be ideal for cationic adsorption; however, they have a small surface area and are macroporous in nature. These factors lead to a reduction in the adsorbent active sites. Chandra and Kim synthesized a polypyrrole-rGO hybrid via noncovalent functionalization of graphene sheets with polypyrrole. ${ }^{\mathbf{4 4}}$ Polypyrrole was shown to grow along the graphene sheets (Fig. 2a), which resulted in a high surface area and mesoporous nature. The composite materials showed highly selective $\mathrm{Hg}$ (II) removal from a solution containing $\mathrm{Hg}$ (II), $\mathrm{Cu}$ (II), $\mathrm{Cd}$ (II), $\mathrm{Pb}$ (II) and $\mathrm{Zn}$ (II) (Fig. 2b). Recently this work has been extended by $\mathrm{Li}$ and colleagues. These authors showed that polypyrrole-rGO nanosheets could be used in the removal of $\mathrm{Cr}(\mathrm{vI})$ from aqueous solutions. ${ }^{45}$ In this study
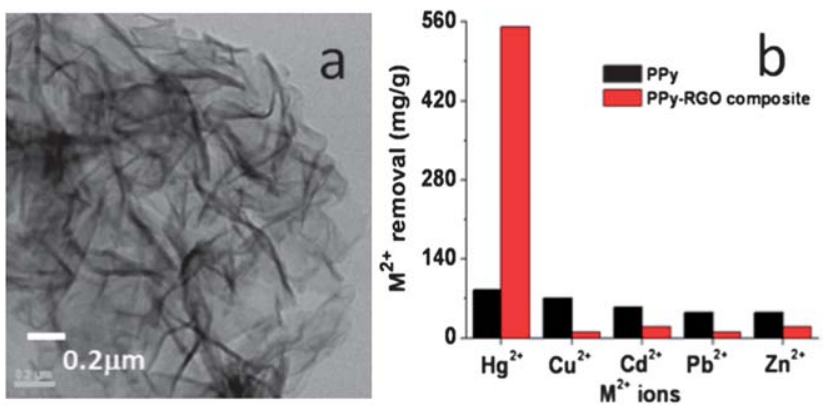

Fig. 2 (a) TEM image of the polypyrrole-rGO composite. (b) Bar graph showing the selective adsorption of mercury from aqueous solution using the polypyrrolegraphene composite. Reproduced from ref. 44. 
the authors used sacrificial $\mathrm{MnO}_{2}$ nanoslices to create the composite material, with the polypyrrole retaining the morphology of the $\mathrm{MnO}_{2}$ nanostructure. As with 3D graphene materials, these polypyrrole materials show an increased adsorption capacity due to a change in the structure of the materials.

Zhang and colleagues showed that chitosan-gelatin/GO monoliths with a high porosity can be used in heavy metal adsorption from aqueous solutions, with the additional benefit of the material being biodegradable. ${ }^{46}$ The material was used for the adsorption of both $\mathrm{Cu}(\mathrm{II})$ and $\mathrm{Pb}$ (II) and showed a high recyclability. Fan et al. reported that a magnetic chitosan-rGO composite material can be utilized in the efficient removal of $\mathrm{Cr}(\mathrm{vI})$ from wastewater. ${ }^{47}$ It is believed that the cyclodextrin inclusion makes the material more stable in solution, as well as offering more binding sites for metal removal from contaminated water. Madarang and co-workers have shown that using a EDTA-GO composite material the $\mathrm{Pb}$ (II) adsorption capacity is higher than for GO or EDTA-rGO. ${ }^{48}$ This is due to the additional binding sites available for the $\mathrm{Pb}(\mathrm{II})$ contaminant when both $\mathrm{GO}$ and EDTA are present in the composite material.

Yang and co-workers showed that $\mathrm{Cu}(\mathrm{II})$ ions could be effectively removed by the interaction between the negatively charged oxygen groups on GO and the positively charged $\mathrm{Cu}$ (II) ions. ${ }^{49}$ Expanding on this topic, multiple groups have shown that GO can also be used in the adsorption $\mathrm{Pb}(\mathrm{II}),{ }^{50,51} \mathrm{Cd}(\mathrm{II})$, $\mathrm{Co}(\mathrm{II})^{52}$ and $\mathrm{U}(\mathrm{VI}) .^{53,54}$ It should be noted that $\mathrm{pH}$ plays a very important role in the adsorption of heavy metals using GO, as the $\mathrm{pH}$ dependent functional groups on the GO surface are the sites for metal adsorption. In the same manner ionic strength affects the adsorption capacity, as the ionic strength determines the concentration of heavy metal cation species available for adsorption. 3D materials have also been applied in the adsorption of contaminants from polluted water. In a report by Sui et al. they showed that conductive graphene-CNT aerogels can be synthesized by the simple ascorbic acid reduction of a GO and CNT dispersion. ${ }^{55}$ This material was then employed effectively in water purification, showing an efficient desalination capacity (633.3 $\mathrm{mg} \mathrm{g}^{-1}$ ) and an impressive heavy metal $\left(\mathrm{Pb}^{2+}, \mathrm{Ag}^{+}, \mathrm{Hg}^{2+}\right.$, and $\left.\mathrm{Cu}^{2+}\right)$ removal capacity.

Vasudevan and Lakshmi have shown that graphene can be used in the effective removal of phosphate ions from aqueous solutions. ${ }^{56}$ Graphene in the study was prepared by liquid phase exfoliation of graphite, which introduces functional groups onto the graphene surfaces which are beneficial during the phosphate adsorption. The authors concluded that this adsorption is spontaneous and chemically irreversible, with a maximum adsorption capacity of $89.4 \mathrm{mg} \mathrm{g}^{-1}$. In a similar way Li and colleagues have shown that exfoliated graphene can be used to adsorb fluoride ions (monolayer adsorption capacity $35.6 \mathrm{mg} \mathrm{g}^{-1}$ at $\mathrm{pH} 7$ and $298 \mathrm{~K}$ ) from solution. ${ }^{57}$ These results showed that even though graphene can be used as an effective adsorbent, it is an irreversible process and as such it cannot be effectively employed in industrial settings.

2.1.2 Adsorption of organic pollutants. Graphene-based materials have been successfully applied in the adsorption of organic pollutants in the form of dyes, polycyclic aromatic hydrocarbons and gasoline. The groups of Zhu and Pradeep have shown that graphene can be successfully applied in the adsorption of various dyes from polluted water. ${ }^{31,58}$ In these graphene materials, the adsorption is determined by physisorption between the pollutants and the graphene surface, as such the larger the surface area the greater the adsorption capacity.

Wang and colleagues reported that magnetic graphene nanocomposites could be used for the efficient removal of fuchsin dye from contaminated water. The authors showed that a quick adsorption time coupled with a high removal efficiency makes the material suitable for water purification. ${ }^{33}$ Recently, Fan et al. showed that the adsorption capacity of methylene blue (MB) from polluted water could be improved by using a magnetic chitosan-rGO composite material. ${ }^{59}$ The magnetic chitosan-rGO material shows an improved adsorption capacity for MB due to an electrostatic mechanism between the charged amino acid groups and MB. This is evident due to the adsorption dependence on $\mathrm{pH}$ and ionic strength. In the same manner, various other groups have reported on the adsorption capacities of iron containing magnetic graphene composite materials, a table of these important results is included for reference, Table 1.

Li et al. have prepared a magnetic Ni-rGO nanocomposite by the simultaneous hydrazine reduction of $\mathrm{GO}$ and $\mathrm{NiCl}_{2} \cdot{ }^{29}$ The composite showed complete adsorption of the organic dyes $\mathrm{RhB}$ and $\mathrm{MB}$ from water within 4 hours. Recently, Li et al. have expanded on this work by showing that a Ni-rGO nanocomposite material can be effectively used in the removal of aromatic compounds (benzene, toulene and dimethylbenzene) from solution. This Ni-rGO material holds promise for

Table 1 Magnetic graphene adsorbents used in the removal of organic pollutants

\begin{tabular}{|c|c|c|c|}
\hline Composite & Synthesis & Removal of pollutant & Ref. \\
\hline Fe-rGO & In situ reduction of $\mathrm{FeCl}_{3}-\mathrm{GO}$ by $\mathrm{NaBH}_{4}$ & Methyl blue & 70 \\
\hline \multirow[t]{3}{*}{$\mathrm{Fe}_{3} \mathrm{O}_{4}-\mathrm{rGO}$} & Redox reaction with $\mathrm{FeCl}_{3}$, NaOAc, EG/DEG & Malachite green-rhodamine B & 71 \\
\hline & In situ conversion of $\mathrm{FeCl}_{3}$ to $\mathrm{Fe}_{3} \mathrm{O}_{4}$ and reduction of GO & Methylene blue & 72 \\
\hline & Chemical deposition of $\mathrm{Fe}_{3} \mathrm{O}_{4}$ on $\mathrm{GO}$ followed by reduction with $\mathrm{N}_{2} \mathrm{H}_{4} \cdot \mathrm{H}_{2} \mathrm{O}$ & Methylene blue, congo red & 73 \\
\hline $\mathrm{Fe}_{3} \mathrm{O}_{4}-\mathrm{GO}, \mathrm{Fe}_{3} \mathrm{O}_{4}-\mathrm{rGO}$ & Hydrolysis with $\mathrm{FeCl}_{3} \cdot 6 \mathrm{H}_{2} \mathrm{O}, \mathrm{FeSO}_{4} \cdot 7 \mathrm{H}_{2} \mathrm{O}, \mathrm{NH}_{3} / \mathrm{N}_{2} \mathrm{H}_{4} \cdot \mathrm{H}_{2} \mathrm{O}$ & 1-Naphthalymine 1-naphthol & 74 \\
\hline $\mathrm{FeC}_{2} \mathrm{O}_{4}-\mathrm{rGO}$ & Chemical deposition method with using $\mathrm{FeSO}_{4} \cdot 7 \mathrm{H}_{2} \mathrm{O}$ and $\mathrm{Na}_{2} \mathrm{C}_{2} \mathrm{O}_{4}$ & Methyl orange & 75 \\
\hline
\end{tabular}


application in water remediation as it is easily recycled and it can be separated from the purified water magnetically. ${ }^{60}$ Further studies by the Li group have shown that by tuning the properties of the nanocomposite materials using metal/metal oxide nanoparticles, the recycling ability, adsorption time and adsorption capacities can be modified. ${ }^{\mathbf{6 1 , 6 2}}$ In these studies it can be seen that the ferromagnetic hematite-graphene nanocomposite outperforms a similar $\mathrm{Cu}_{2} \mathrm{O}-\mathrm{rGO}$ nanocomposite with respect to adsorption time in the removal of rhodamine $\mathrm{B}$ from water. This observed increase in adsorption capacity could be attributed to the different surface areas of the materials, as nanoparticles have the ability to decrease the restacking ability of rGO.

Due to the advantages of low cost, solution processability and unique structure, rGO has been utilized to fabricate superhydrophobic and superoleophilic materials which can be employed in the cleanup of oil spillage and chemical leakage. The use of 3D graphene-based materials as adsorbents was demonstrated by Cong et al. The 3D material was formed by a GO self-assembly process and could be successfully applied in the removal of gasoline from water. ${ }^{42}$ This material could be made magnetic by the inclusion of $\mathrm{Fe}_{3} \mathrm{O}_{4}$ during the selfassembly process, which is an added benefit in water purification methods. The use of $3 \mathrm{D}$ graphene-based materials as adsorbents has been extended to the removal of dyes. ${ }^{32,34}$ The advantage in using these $3 \mathrm{D}$ graphene-based materials is that they can be separated from solution easily, without magnetic or centrifugation separation, thereby making them easily regenerable and reusable.

In a study by Nguyen and colleagues, rGO-coated porous scaffolds were simply prepared by dipping a melamine sponge into graphene dispersion in ethanol and then drying the material. ${ }^{63}$ The rGO-coated melamine sponges displayed superhydrophobicity and as such they could be used to adsorb oils and organic solvents from polluted water, see Fig. 3.
In another study Dong and co-workers synthesized graphenebased 3D hybrids composed of monoliths of graphene and CNTs using a two-step chemical vapor deposition method. ${ }^{64}$ These 3D foams are similar to the rGO-coated melamine sponges in that they selectively adsorb oils and organic solvents from polluted water (Fig. 3). Importantly these 3D foams have a very large internal area for adsorption and as such can retain the absorbents effectively.

Zhang et al. have shown that a graphene-coated biochar material can be utilized as an adsorbent of polyaromatic hydrocarbons. In this study the authors showed that the adsorption capacity of the biochar could be increased 20 times when coated with graphene. ${ }^{65}$ In another study Nguyen-Phan and co-workers have shown that a P25-rGO composite material can be used in the adsorption of methylene blue from aqueous solution, where the adsorption capacity is determined by the self-assembly process of P25 on the graphene sheets. ${ }^{66}$ When P25 self-assembles in nanosheets, a higher adsorption capacity is observed compared to nanoribbons or nanotubes. This increase in adsorption is due to an increased surface area observed in the nanosheets compared to the other nanostructures. Recently Nguyen-Phan et al. have reported that a 3Dwormhole like mesoporous titanosilicate-rGO could be used in the removal of methylene blue from wastewater. ${ }^{67}$ In this study they investigated the effect of the Ti dopant in $\mathrm{Si}$ and it was noted that when the Ti concentration is large (i.e. $20 \mathrm{~mol} \%$ ), the adsorption by the composite is fast. However, this increase in $\mathrm{Ti}$ concentration results in a negative effect on the photocatalytic dye degradation activity.

Li et al. have produced a $\mathrm{Mg}(\mathrm{OH})_{2}-\mathrm{rGO}$ composite by the simultaneous reduction of $\mathrm{MgCl}_{2}$ and $\mathrm{GO}$ using $\mathrm{NaOH}{ }^{28}$ $\mathrm{Mg}(\mathrm{OH})_{2}$ helped rGO to maintain a mesoporous structure and high surface area which proved to be beneficial for removal of MB from water. The composite was easily removed from solution by filtration and could be reused by a simple ethanol
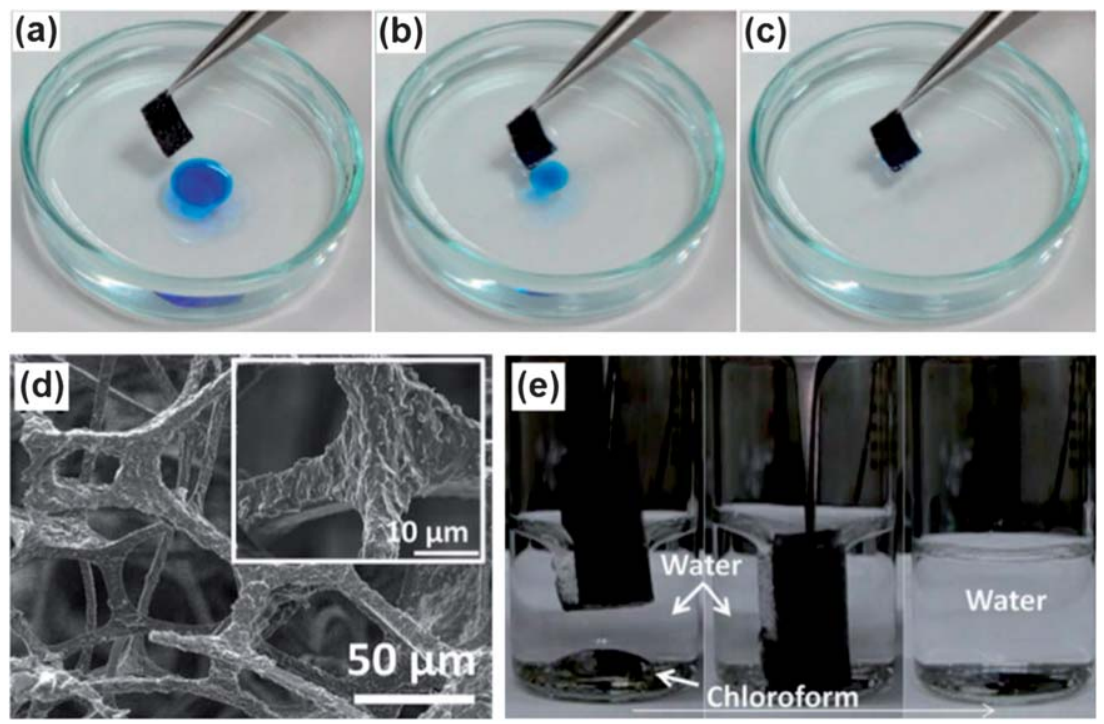

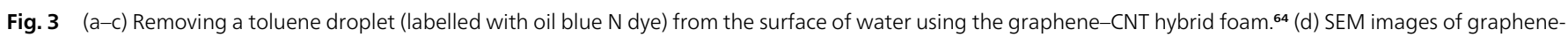
coated melamine sponge. (e) The removal process of chloroform from water using the graphene-based sponges. ${ }^{63}$ Adapted from ref. 63 and 64. 
washing step. Pan and Liu have shown that by including rGO with CdS nanoparticles, the methyl orange adsorption capacity of the material could be increased 12 times. ${ }^{68}$ This result is important as the efficiencies of photocatalytic materials are not only affected by graphene's superior electronic properties but also by its large surface area.

This synthesized material also proved very effective for organic pollutant removal, as has been confirmed by Tiwari et $a l .{ }^{69}$ In this study it was shown that these $3 \mathrm{D}$ materials are more efficient absorbers of pollutants than 2D graphene materials, as they avoid the restacking problem that occurs during the formation of rGO materials. Importantly, in contrast to $2 \mathrm{D}$ graphene these $3 \mathrm{D}$ materials displayed controllable desorption of the pollutants. This desorption should allow these types of 3D architecture to be applied in pollution cleanup, where reuse is essential.

\subsection{Water remediation by photocatalysts}

A photocatalyst absorbs UV and/or visible light irradiation from sunlight or an illuminated light source as shown in Fig. 4. The electrons in the valence band (VB) of the photocatalyst are excited to the conduction band (CB), while the holes are left in the valence band. This, therefore, creates the negative-electron $\left(\mathrm{e}^{-}\right)$and positive-hole $\left(\mathrm{h}^{+}\right)$pairs. This stage is referred to the semiconductor's "photo-excited" state, and the energy difference between the valence band and the conduction band is known as the "band gap". This must correspond to the wavelength of the light for it to be effectively absorbed by the photocatalyst. The electron-hole pairs that are generated in this way migrate towards the surface where they can initiate redox reactions with adsorbates. Reactions with the positive holes are linked to oxidation and reactions with the electrons to reduction. Degradation/disinfection of toxic pollutants operates through the formation of hydroxyl radicals $\left(\mathrm{OH}^{-}\right)$, which have very low reaction selectivity. These $\mathrm{OH}^{-}$radicals drive the oxidation of pollutants to complete mineralization i.e. less reactive pollutants.

The limiting factor in semiconductor catalysis efficiency is the rapid recombination of photogenerated electrons and holes, which significantly affects practical applications. Graphene and GO-based materials are promising candidates for photocatalytic water remediation due to their high adsorption capacity of dyes, extended light absorption range, enhanced charge separation and charge transport properties. ${ }^{76-78}$ These

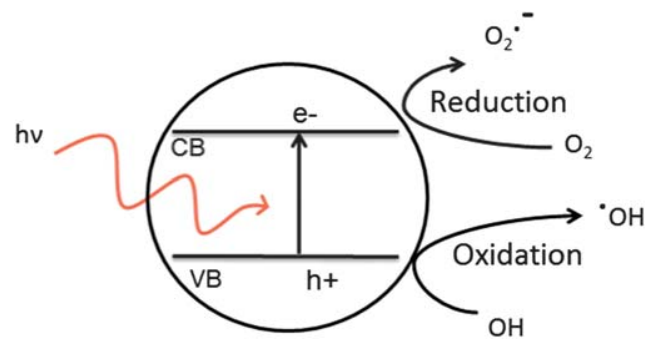

Fig. 4 Fundamental principle of semiconductor-based photocatalysts. properties have been shown to increase the photoconversion efficiency of $\mathrm{rGO} / \mathrm{GO}$ containing photocatalytic materials. Various methods have been employed to produce rGO/GO photocatalytic materials of which in situ growth, hydrothermal/ solvothermal, solution mixing and microwave assisted growth are predominantly used at present. Due to the large number of articles published on photocatalytic organic pollutant degradation using graphene composites, a table (Table 2) summarizing the data has been included at the end of Section 2.2.2.

2.2.1 Photocatalytic degradation of ionic pollutants. Wang et al. have shown that three different nanocarbon- $\mathrm{TiO}_{2}$ nanocomposites can be prepared by the self-assembly of colloidal $\mathrm{TiO}_{2}$ nanoparticles on the respective nanocarbon (SWCNT, $\mathrm{C}_{60}$ and graphene) surfaces by a thermal reaction. ${ }^{79}$ They showed that the $\mathrm{rGO}-\mathrm{TiO}_{2}$ sample exhibited the highest photocatalytic activity of the as prepared samples, with an increase of performance in the visible region (3.46 times) compared to commercially available P25. This increase in photocatalytic activity is believed to be due to an increase in conductivity due to the graphene substrate, as well as a more uniform distribution of nanoparticles on the graphene surface compared to the other nanocarbons.

Utilizing a similar deposition method, Zhang et al. prepared a P25-rGO composite which showed a remarkable increase in visible light photocatalytic activity of 7 times that of the bare P25 catalyst. ${ }^{80}$ Liu et al. synthesized $\mathrm{TiO}_{2}-\mathrm{rGO}$ composites via the microwave-assisted reduction of $\mathrm{GO}$ in a $\mathrm{TiO}_{2}$ suspension. ${ }^{81}$ The $\mathrm{TiO}_{2}-\mathrm{rGO}$ composites exhibited enhanced photocatalytic performance for the reduction of $\mathrm{Cr}(\mathrm{vI})$ with a maximum removal rate of $91 \%$ under UV light irradiation as compared with pure $\mathrm{TiO}_{2}$ (83\%) and commercial P25 (70\%) due to the increased light absorption intensity and range. Additionally, there is a reduction in electron-hole pair recombination in $\mathrm{TiO}_{2}$ with the introduction of rGO. Zhang et al. have shown that $\mathrm{TiO}_{2}$ can additionally be linked covalently to GO through an esterification reaction between the hydroxyl group of the $\mathrm{TiO}_{2}$ and the carboxylic acid groups on the GO sheets. ${ }^{82}$ This leads to an enhanced photocatalytic degradation of $\operatorname{Cr}(\mathrm{vI})$, when there is only $5 \mathrm{wt} \%$ GO loading in the composite material. It seems that in all these reported studies using graphene as a substrate the increase in photocatalytic activity can be attributed to a reduction in electron-hole recombination, as well as an increase in conductivity in the materials due to graphene's inherent properties.

Liu et al. reported the formation of ZnO-rGO composites synthesized via the microwave-assisted reduction of zinc sulfate in an aqueous GO dispersion. ${ }^{83}$ The ZnO-rGO composite exhibited an enhanced photocatalytic performance in the reduction of $\mathrm{Cr}(\mathrm{vI})$ with a removal rate of $98 \%$ under UV light irradiation as compared with pure $\mathrm{ZnO}$ (58\%) due to an increased light absorption intensity and range. The same group has additionally reported on the $\mathrm{ZnO}$ assisted photocatalytic reduction of $\mathrm{GO}$, where the resulting composite material was likewise used in the photocatalytic reduction of $\mathrm{Cr}(\mathrm{vI}){ }^{{ }^{84}}$

Liu et al. synthesized CdS-rGO composites via the microwave-assisted reduction of $\mathrm{GO}$ in a $\mathrm{CdS}$ precursor solution. ${ }^{\mathbf{8 5}}$ CdS-rGO composites exhibited enhanced photocatalytic 
performance for the reduction of $\mathrm{Cr}(\mathrm{vI})$ with a maximum removal rate of $92 \%$ under visible light irradiation as compared with pure CdS (79\%) due to the increased light absorption intensity and reduction of electron-hole pair recombination in CdS with the introduction of rGO.

Ma et al. have shown that $\mathrm{rGO}-\mathrm{Bi}_{2} \mathrm{WO}_{6}$ nanocomposites, with $20 \%$ rGO, can be used in the reduction of $\mathrm{Cr}(\mathrm{vI})$ from solutions. ${ }^{86}$ The authors showed that a simple sonication and washing process can be used to regenerate the composite material. Neppolian and colleagues have shown that the introduction of Pt into a $\mathrm{TiO}_{2}-\mathrm{rGO}$ composite material leads to an enhanced degradation of the dodecylbenzenesulfonate anion by a factor $3 .^{87}$ An et al. have shown that an $\operatorname{In}_{2} \mathrm{~S}_{3}$ nanosheetrGO composite material can be produced using a one pot procedure. ${ }^{88}$ The resulting material was then used to reduce $\mathrm{Cr}(\mathrm{vI})$ as well as decompose the organic dye methyl orange in polluted water. As with the adsorption of pollutants, many of the materials produced for photocatalytic degradation can be widely applied to degrade both ionic and organic pollutants.

2.2.2 Photocatalytic degradation of organic pollutants. Many organic pollutants are found in various water sources. These pollutants belong to various chemical classes such as pesticides, fertilizers, dyes, hydrocarbons, phenols, plasticizers, biphenyls, detergents, oils, greases, pharmaceuticals, etc. Liu and colleagues have shown that $\mathrm{TiO}_{2}$ nanorods can be selfassembled on GO sheets at a water-toluene interface. This selfassembly leads to a significant increase in photocatalytic activity, which was confirmed by the degradation of methylene blue (MB) under UV light irradiation. The large enhancement in photocatalytic activity is caused by a decrease in charge recombination, as well as the effective absorption of $\mathrm{MB}$ on rGO. ${ }^{89}$ In another study Zhang et al. showed that the photoactivity of the rGO-P25 composite showed enhanced activity toward the photodegradation of MB compared to bare P25 and P25-CNTs under both UV and visible light irradiation (see Fig. 5). ${ }^{108}$ rGO-TiO 2 composites have also been produced using solvothermal methods as has been shown by Qi who prepared a P25-rGO nanocomposite using GO and P25 as raw materials. ${ }^{90}$

Du et al. reported on the incorporation of rGO into hierarchically ordered macro-mesoporous titania frameworks by in situ reduction of GO added during the self-assembly process (Fig. 6). ${ }^{91}$ The incorporation of interconnected macropores into mesoporous films improves the mass transport through the film, reduces the length of the mesopore channel, and increases the accessible surface area of the thin film, whereas the introduction of graphene effectively suppresses the charge recombination. The Acid Orange 7 (AO7) degradation constants for the macro-mesoporous titania films without and with graphene are 11 and 17 times higher than those of pure mesoporous titania films, respectively. These nanostructured materials show an improved catalytic performance compared to the normally used 2D graphene materials as they increase the accessible reactive sites for photocatalytic degradation.
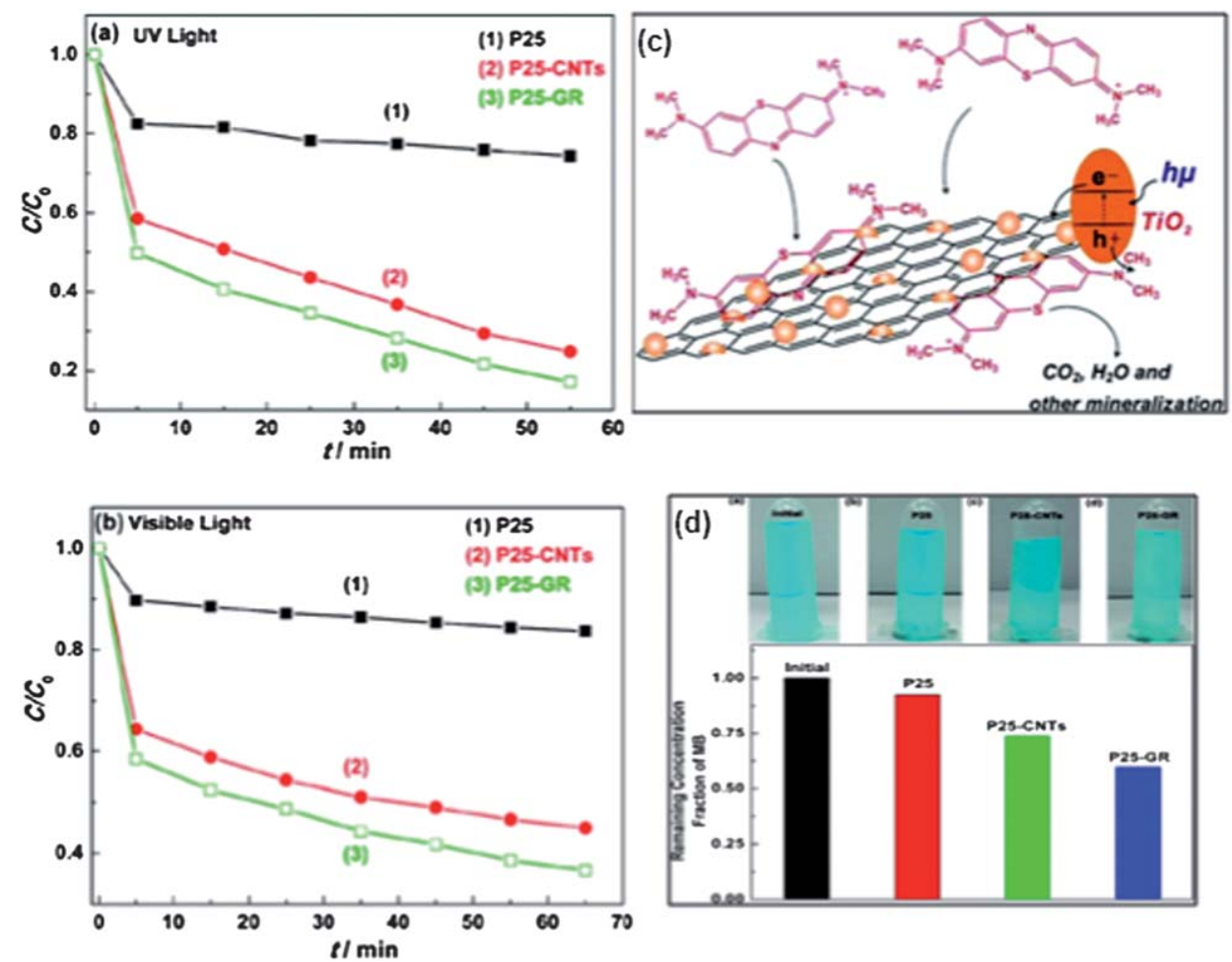

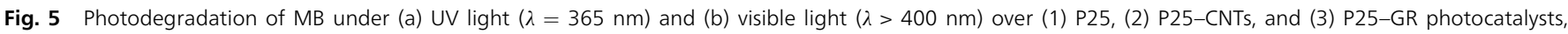

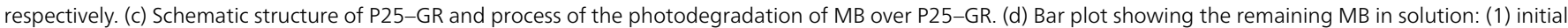

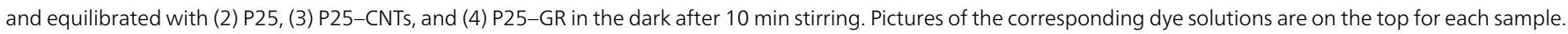
Adapted with permission from H. Zhang, X. Lv, Y. Li, Y. Wang and J. Li, ACS Nano, 2010, 4, 380. Copyright 2010 American Chemical Society. 


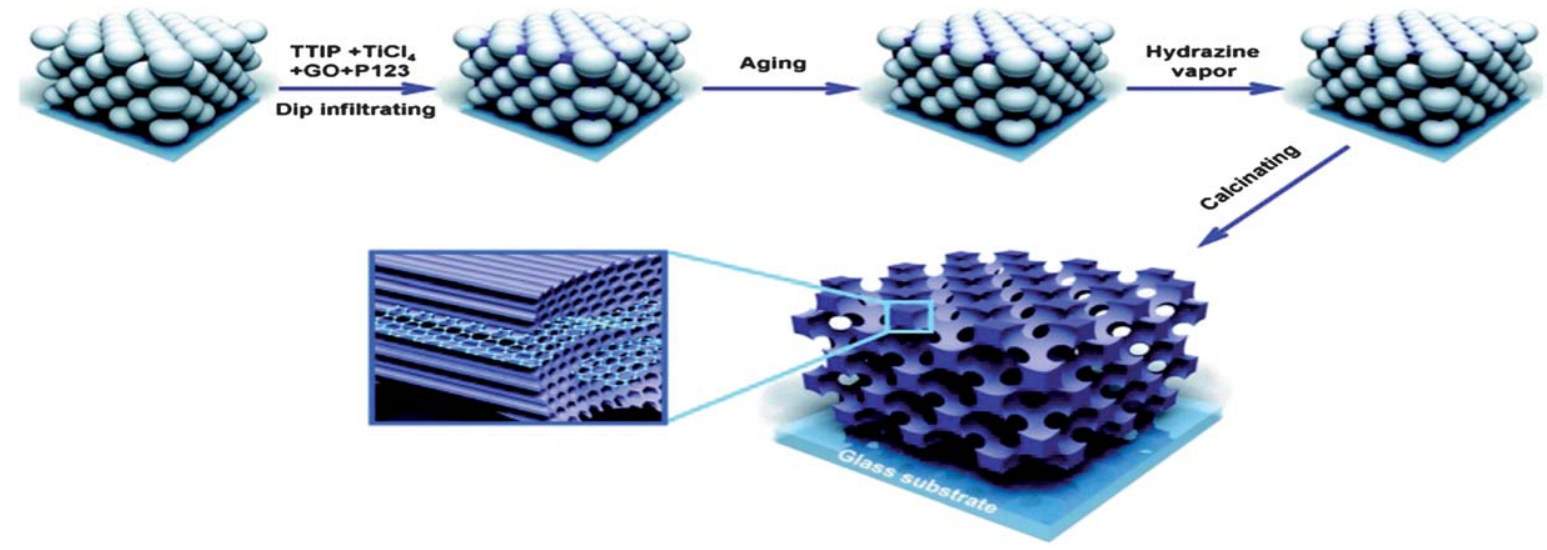

Fig. 6 Illustration for the preparation of a macro-mesoporous $\mathrm{TiO}_{2}$-graphene composite film. Reprinted with permission from J. Du, X. Lai, N. Yang, J. Zhai, D. Kisailus, F. Su, D. Wang and L. Jiang, ACS Nano, 2011, 5, 590. Copyright 2011 American Chemical Society.

Rao et al. synthesized composites of $\mathrm{TiO}_{2}$ nanoparticles with pure graphene as well as boron- and nitrogen-doped graphene and studied the photodegradation of $\mathrm{MB}$ and rhodamine $\mathrm{B}$ $(\mathrm{RhB}){ }^{92}$ They showed that MB which is a good electron donor and has a low ionization energy interacts strongly with electrondeficient boron-doped graphene resulting in fast degradation of the dye. On the other hand, RhB which is not a good electron donor and has a higher ionization energy interacts strongly with electron-rich nitrogen-doped graphene causing a faster degradation of the dye.

It has been recently shown by Humaira et al. that a $\mathrm{SnO}_{2}-\mathrm{rGO}$ nanocomposite shows an enhanced photocatalytic degradation activity for the organic dye MB under sunlight compared to bare $\mathrm{SnO}_{2}$ nanoparticles. ${ }^{93}$ These results are a great improvement over similar work published by Zhang and colleagues. ${ }^{94}$ This enhancement is believed to be due to an even distribution of $\mathrm{SnO}_{2}$ nanoparticles on the rGO surface which leads to an improved conduction and charge separation in the composite material.

Lv et al. reported a quick and facile microwave-assisted synthesis method to produce ZnO-rGO hybrid composites by reducing a GO dispersion in the presence of zinc nitrate. ${ }^{95}$ The authors studied the photocatalytic performance of the composite in the degradation of MB and the results showed that rGO plays an important role in the enhancement of photocatalytic performance. It was shown that the ZnO-rGO composite with $1.1 \mathrm{wt} \%$ rGO achieved a maximum degradation efficiency of $88 \%$ in a neutral solution under UV light as compared to pure $\mathrm{ZnO}$ (68\%) due to increased light absorption and reduced charge recombination. Yang et al. synthesized a nanocomposite of functionalized graphene sheets (FGS) with ZnO via a thermal treatment method, using GO as a precursor for graphene and $\mathrm{Zn}\left(\mathrm{NH}_{3}\right)_{4} \mathrm{CO}_{3}$ as a precursor for $\mathrm{ZnO}{ }^{96}$ The composites were used in the photocatalytic decomposition of rhodamine 6G, with 96\% degradation under UV light within 100 minutes. Likewise $\mathrm{Xu}$ et al. have shown that rGO hybridized with $\mathrm{ZnO}$ can be used as an efficient photocatalyst. ${ }^{97}$ The authors showed that a small amount of rGO (2 wt\%) improves the photocatalytic activity 4 times that of pristine ZnO. These reports which show that graphene inclusion in composites can change the nanoparticles adsorption range are very important, as the majority of sunlight lies in the visible region and is inaccessible by certain bare nanoparticles. In another study, Liu et al. synthesized $\mathrm{CuO}$ nanoflower-decorated $\mathrm{rGO}$ (CuONF-rGO) nanocomposites. ${ }^{98}$ They demonstrated that the CuONF-rGO nanocomposites exhibited a higher photocatalytic activity toward degradation of $\mathrm{RhB}$ than $\mathrm{CuO}$ nanoparticles or rGO samples.

Gao et al. reported on the formation of a graphene- $\mathrm{Bi}_{2} \mathrm{WO}_{6}$ (rGO-BWO) composite via in situ hydrothermal reduction of a $\mathrm{GO}-\mathrm{Bi}_{2} \mathrm{WO}_{6}$ composite by ethylene glycol. ${ }^{99}$ The as-prepared rGO-BWO photocatalyst showed an enhanced photocatalytic activity for the degradation of $\mathrm{RhB}$ under visible light $(\lambda>$ $420 \mathrm{~nm}$ ). The electronic interaction and charge equilibration between graphene and $\mathrm{Bi}_{2} \mathrm{WO}_{6}$ lead to a shift in the Fermi level and a decrease in the conduction band potential, which has an important influence on the photocatalytic process. The enhanced photocatalytic activity could be attributed to the negative shift in the Fermi level of rGO-BWO and the high migration efficiency of photoinduced electrons, which may suppress the charge recombination effectively.

Hu et al. reported a facile and efficient microwave irradiation strategy for preparing graphene nanosheet-zinc sulfide (GNS$\mathrm{ZnS})$ nanocomposites. ${ }^{100}$ Photoluminescence measurements show that there is photoinduced electron transfer between $\mathrm{ZnS}$ and the GNS. Furthermore, the as-prepared graphene-based nanocomposites show an excellent photocatalytic activity toward the photodegradation of MB. These studies show that the hole-electron recombination is reduced when graphene is used as a substrate in the absorbent material. This is a property that is seen in all photocatalytically active graphene composites and is due to the efficient transfer of electrons through the graphene sheet away from the holes.

Chen et al. reported that a nitrogen-doped graphene-ZnSe nanocomposite (GN-ZnSe) could be prepared by a one-pot hydrothermal process at low temperature. ${ }^{101} \mathrm{ZnSe}$ nanorods composed of ZnSe nanoparticles were found to deposit on the surface of the GN sheets through a self-assembly process. 
The as-prepared nanocomposites exhibited remarkably enhanced photocatalytic activities for the bleaching of methyl orange (MO) dye under visible-light irradiation.

Xiong and colleagues showed that the simple addition of $\mathrm{CuCl}_{2}$ or $\mathrm{CuNO}_{3}$ to a rGO solution resulted in $\mathrm{Cu}$ modified rGO which exhibited an excellent photocatalytic activity. ${ }^{\mathbf{1 0 2}}$ The possible mechanism for the reduction of organic dye using the $\mathrm{Cu}-\mathrm{rGO}$ composite is shown in Fig. 7. Likewise Au nanoparticles have been deposited on the surface of rGO through the spontaneous chemical reduction of chloroauric acid $\left(\mathrm{HAuCl}_{4}\right)$ by rGO. ${ }^{103}$

Zhu and co-workers adopted an alternative method, whereby a water-oil system was used to produce GO enwrapped $\mathrm{Ag}-\mathrm{AgX}$

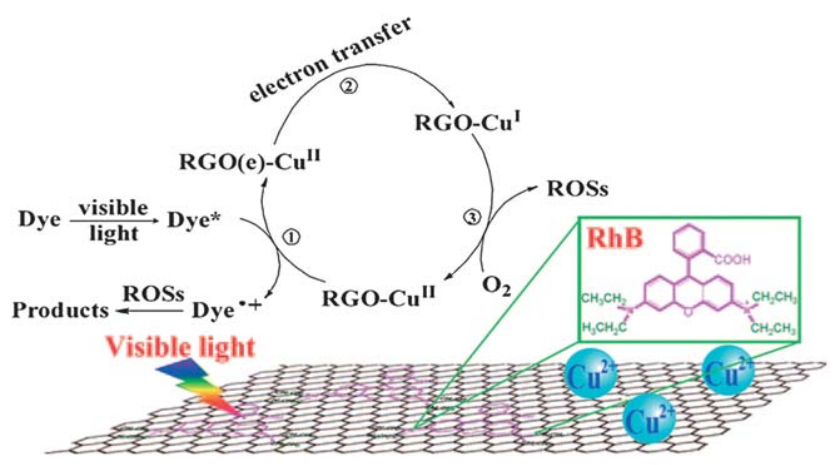

Fig. 7 Possible mechanism of photosensitized degradation of dyes over an rGOCu composite under visible-light irradiation. Copyright 2011 Wiley. Used with permission from Z. Xiong, L. L. Zhang and X. S. Zhao, Visible-light-induced dye degradation over copper-modified reduced graphene oxide, Chem.-Eur. J., Wiley.
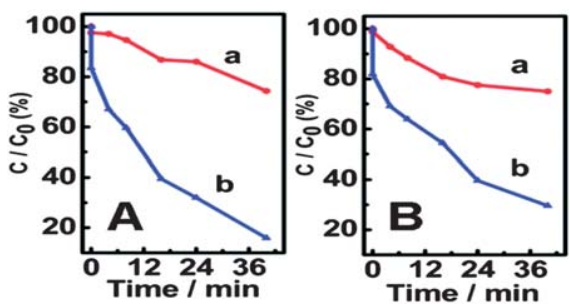

Fig. 8 (A) Photocatalytic activities of nanospecies $\mathrm{Ag}-\mathrm{AgBr}(\mathrm{a})$ and $\mathrm{Ag}-\mathrm{AgBr}-\mathrm{GO}$ (b) for photodegradation of $\mathrm{MO}$ molecules under visible-light irradiation. (B) Those of nanospecies $\mathrm{Ag}-\mathrm{AgCl}(\mathrm{a})$ and $\mathrm{Ag}-\mathrm{AgCl}-\mathrm{GO}(\mathrm{b})$ Reprinted with permission from M. Zhu, P. Chen and M. Liu, ACS Nano, 2011, 5, 4529. Copyright 2011 American Chemical Society.
(X = Br, Cl) composites. ${ }^{104}$ These $\mathrm{Ag}-\mathrm{AgX}-\mathrm{GO}$ hybrid composites showed high photocatalytic activity under visible light irradiation as illustrated in Fig. 8. Interestingly, this photocatalytic activity comes from surface plasmons and not from the traditional light excitations that occur in traditional photocatalysts. As such this work demonstrated that graphene as a substrate material is also able to increase the plasmonic effect in a material that displays plasmonic photocatalytic degradation.

It has been shown by Liao et al. that a GO modified g- $\mathrm{C}_{3} \mathrm{~N}_{4}$ composite material (GO-g- $\mathrm{C}_{3} \mathrm{~N}_{4}$ ) with an efficient photocatalytic capability can be fabricated using a simple sonication technique. ${ }^{105}$ This material showed no obvious decrease in photocatalytic activity after 5 dye degradation cycles. In this study the authors showed that the efficiency of the material is increased due to an increased charge separation at the heterojunction between the two constituents. Zhao et al. pillared rGO platelets with carbon nanotubes (CNTs) using a CVD method with acetonitrile (as the carbon source) and nickel nanoparticles (as the catalysts), as shown in Fig. 9. ${ }^{106}$ They believe that the enhanced photocatalytic activity observed is due to the unique porous nature of the material as well as the exceptional electron transfer properties of rGO.

2.2.3 Photocatalytic disinfection of biological pollutants. The different types of microbes (viruses, bacteria, fungi, algae, amoebas, and plankton) present in wastewater are responsible for various diseases. GO has the benefit of being biocompatible $^{\mathbf{1 3 2}}$ as well as exhibiting anti-bacterial properties. ${ }^{133}$ These properties allow the material to be applied to the remediation of biological pollutants (see Section 4). Liu et al. have developed a water-toluene two-phase process for self-assembling $\mathrm{TiO}_{2}$ nanorods on GO sheets. ${ }^{130}$ Using this method the authors showed a much improved antibacterial activity towards E. coli cells. Akhavan and Ghaderi have reported the formation of $\mathrm{TiO}_{2}$-graphene thin films via photocatalytic self reduction. ${ }^{\mathbf{1 3 4}}$ This $\mathrm{TiO}_{2}$-graphene composite material shows an improvement in antibacterial activity of a factor 7.5 compared to a pure $\mathrm{TiO}_{2}$ film. It is important to note in these studies that the disinfection capacity is related to the photocatalytic material, and the graphene acts as an enhancer by increasing the charge separation.

Akhavan and colleagues have shown that an rGO-tungsten oxide composite material can be formed by deposition of the WO nanoparticles onto GO and subsequent annealing. ${ }^{135}$ The material formed was shown to be effective in the photocatalytic

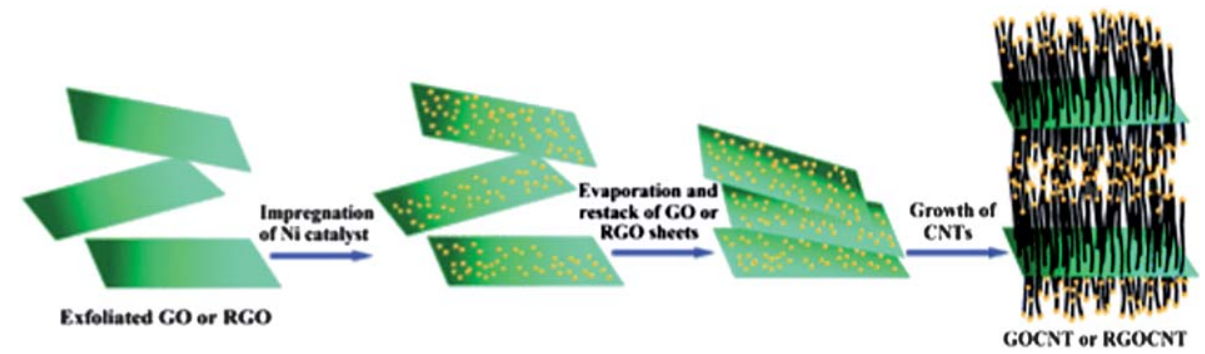

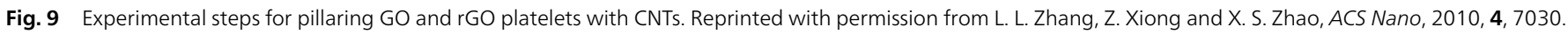
Copyright 2010 American Chemical Society. 
Table 2 Photocatalytic degradation of organic pollutants

\begin{tabular}{|c|c|c|c|c|c|}
\hline Photocatalysts & Preparation strategy & Photocatalytic experiments & $\begin{array}{l}\text { Performance compared } \\
\text { to bare nanoparticles }\end{array}$ & Irradiation & Ref. \\
\hline P25-rGO & Hydrothermal method & Photodegradation of $\mathrm{MB}$ & 2.32 times higher than P25 & Visible & 107 \\
\hline P25-rGO & Hydrothermal method & Photodegradation of $\mathrm{MB}$ & 4.33 times higher than $\mathrm{P} 25$ & Visible & 108 \\
\hline $\mathrm{TiO}_{2}-\mathrm{rGO}$ & Self-assembly method & Degradation of MO & 3.46 times higher than P25 & Visible & 79 \\
\hline $\mathrm{TiO}_{2}-\mathrm{rGO}$ & Self-assembly method & Photodegradation of MB & 7.0 times higher than pure $\mathrm{P} 25$ & Visible & 80 \\
\hline $\mathrm{SnO}_{2}-\mathrm{rGO}$ & Redox method & Photodegradation of RhB & 2.24 times higher than P25 & Visible & 94 \\
\hline $\mathrm{TiO}_{2}-\mathrm{rGO}$ & Hydrothermal method & Photodegradation of MB & 13.04 times higher than P25 & Visible & 109 \\
\hline $\mathrm{TiO}_{2}-\mathrm{rGO}$ film & Sonication/self reduction & $\begin{array}{l}\text { Photodegradation of } \\
2,4 \text {-dichlorophenoxyacetic } \\
\text { acid }(2,4-\mathrm{D})\end{array}$ & 4.0 times higher than $\mathrm{TiO}_{2}$ film & UV & 110 \\
\hline $\mathrm{TiO}_{2}-\mathrm{rGO}$ & Hydrothermal method & Photodegradation of RhB & 2.94 times higher than P25 & UV & 111 \\
\hline $\mathrm{TiO}_{2}-\mathrm{rGO}$ & Hydrothermal method & $\begin{array}{l}\text { Photodegradation of } \\
\text { malachite green }\end{array}$ & $\begin{array}{l}3.09 \text { times higher than } \mathrm{TiO}_{2} \\
\text { nanotubes }\end{array}$ & UV & 112 \\
\hline rGO@ $\mathrm{TiO}_{2}$ & Sonication/self reduction & Photodegradation of MB & $\begin{array}{l}2.20 \text { times higher than a } \\
\text { physical mixture of } \mathrm{G}-\mathrm{P} 25 \\
(1: 3)\end{array}$ & UV & 113 \\
\hline $\mathrm{TiO}_{2}-\mathrm{B}-\mathrm{doped}$ & Hydrothermal method & Photodegradation of $\mathrm{MB}$ & 4.30 times higher than $\mathrm{TiO}_{2}$ & UV-vis & 92 \\
\hline rGO & & Photodegradation of RhB & 1.6 times higher than $\mathrm{TiO}_{2}$ & UV-vis & \\
\hline $\begin{array}{l}\mathrm{TiO}_{2}-\mathrm{N} \text {-doped } \\
\mathrm{rGO}\end{array}$ & Hydrothermal method & $\begin{array}{l}\text { Photodegradation of } \mathrm{MB} \\
\text { Photodegradation of } \mathrm{RhB}\end{array}$ & $\begin{array}{l}2.4 \text { times higher than } \mathrm{TiO}_{2} \\
3.2 \text { times higher than } \mathrm{TiO}_{2}\end{array}$ & $\begin{array}{l}\text { UV-vis } \\
\text { UV-vis }\end{array}$ & 92 \\
\hline $\mathrm{TiO}_{2}-\mathrm{rGO}-\mathrm{TiO}_{2}$ & Hydrothermal method & Photodegradation of $\mathrm{MB}$ & 4 times higher than $\mathrm{TiO}_{2}$ & UV-vis & 114 \\
\hline $\begin{array}{l}\mathrm{TiO}_{2}-\mathrm{rGO} / \\
\mathrm{MCM}-41\end{array}$ & Hydrothermal method & $\begin{array}{l}\text { Photodegradation of } \\
\text { 2-propanol }\end{array}$ & $\begin{array}{l}1.7 \text { times higher than } \\
\mathrm{TiO}_{2} / \mathrm{MCM}-41\end{array}$ & UV & 115 \\
\hline $\mathrm{Ag}-\mathrm{TiO}_{2}-\mathrm{rGO}$ & Hydrothermal method & Photodegradation of MB & Not reported & Visible & 116 \\
\hline $\begin{array}{l}\mathrm{UC}-\mathrm{P} 25-\mathrm{rGO} \\
\mathrm{UC}=\mathrm{YF}_{3}: \mathrm{Yb}^{3+}, \mathrm{Tm}^{3+}\end{array}$ & Hydrothermal method & Photodegradation of MO & 2.88 times higher than $\mathrm{P} 25$ & Visible & 90 \\
\hline $\mathrm{ZnO}-\mathrm{FGS}$ & $\begin{array}{l}\text { Thermal treatment } \\
\text { method }\end{array}$ & Photodegradation of Rh $6 \mathrm{G}$ & Not reported & UV & 96 \\
\hline $\mathrm{ZnO}-\mathrm{rGO}$ & Sonochemical method & Photodegradation of MB & 4.45 times higher than $\mathrm{ZnO}$ & UV & 97 \\
\hline $\mathrm{ZnO}-\mathrm{rGO}$ & Sonication method & Photodegradation of MB & 2.25 times higher than $\mathrm{ZnO}$ & UV & 117 \\
\hline $\mathrm{CuO}-\mathrm{rGO}$ & Solvothermal method & $\begin{array}{l}\text { Photodegradation of } \mathrm{RhB} \\
\text { in the presence of } \mathrm{H}_{2} \mathrm{O}_{2}\end{array}$ & 2.50 times higher than $\mathrm{CuO}$ & UV & 98 \\
\hline $\mathrm{SnO}_{2}-\mathrm{rGO}$ & Redox method & Photodegradation of MB & 24.86 times higher than $\mathrm{SnO}_{2}$ & Visible & 93 \\
\hline $\mathrm{WO}_{3}-\mathrm{rGO}$ & Hydrothermal method & Photodegradation of RhB 6G & $\begin{array}{l}53 \text { times higher than } \mathrm{WO}_{3} \\
\text { particles }\end{array}$ & Visible & 118 \\
\hline $\mathrm{CdS}-\mathrm{rGO}$ & Solvothermal method & Photodegradation of MB & 2.5 times higher than CdS & Visible & 119 \\
\hline $\mathrm{CdS}-\mathrm{rGO}$ & Hydrothermal method & Photodegradation of MO & 7.86 times higher than CdS & Visible & 120 \\
\hline ZnS-rGO & $\begin{array}{l}\text { Microwave assisted } \\
\text { method }\end{array}$ & Photodegradation of MB & 4 times higher than P25 & UV & 100 \\
\hline $\mathrm{Cu}-\mathrm{rGO}$ & Solvothermal method & Photodegradation of RhB & 2.94 times higher than P25 & Visible & 102 \\
\hline $\mathrm{Au}-\mathrm{rGO}$ & Reduction method & $\begin{array}{l}\text { Photodegradation of } \mathrm{RhB} \\
\text { Photodegradation of } \mathrm{MB} \\
\text { Photodegradation of } \\
\text { orange II }\end{array}$ & $\begin{array}{l}1.77 \text { times higher than P25 } \\
\text { 8.36 times higher than P25 } \\
0.19 \text { times higher than P25 }\end{array}$ & Visible & 103 \\
\hline $\mathrm{ZnFe}_{2} \mathrm{O}_{4}-\mathrm{rGO}$ & Hydrothermal method & $\begin{array}{l}\text { Photodegradation of } \mathrm{MB} \\
\text { in the presence of } \mathrm{H}_{2} \mathrm{O}_{2}\end{array}$ & 4.50 times higher than $\mathrm{ZnFe}_{2} \mathrm{O}_{4}$ & Visible & 121 \\
\hline $\mathrm{MnFe}_{2} \mathrm{O}_{4}-\mathrm{rGO}$ & Hydrothermal method & $\begin{array}{l}\text { Photodegradation of } \mathrm{MB} \\
\text { Photodegradation of } \mathrm{MB} \\
\text { Photodegradation of } \\
\text { phenol }\end{array}$ & $\begin{array}{l}\text { 9.62 times higher than } \mathrm{MnFe}_{2} \mathrm{O}_{4} \\
1.33 \text { times higher than } \mathrm{MnFe}_{2} \mathrm{O}_{4} \\
1.13 \text { times higher than } \mathrm{MnFe}_{2} \mathrm{O}_{4}\end{array}$ & $\begin{array}{l}\text { Visible } \\
\text { UV } \\
\text { UV }\end{array}$ & 122 \\
\hline $\mathrm{NiFe}_{2} \mathrm{O}_{4}-\mathrm{rGO}$ & Hydrothermal method & Photodegradation of MB & Not reported & Visible & 123 \\
\hline $\mathrm{CoFe}_{2} \mathrm{O}_{4}-\mathrm{rGO}$ & Solvothermal method & $\begin{array}{l}\text { Photodegradation of } \mathrm{RhB} \\
\text { and } \mathrm{MB}\end{array}$ & Not reported & Visible & 124 \\
\hline $\mathrm{Bi}_{2} \mathrm{WO}_{6}-\mathrm{rGO}$ & Solvothermal method & Photodegradation of RhB & 1.80 times higher than $\mathrm{Bi}_{2} \mathrm{WO}_{6}$ & Visible & 125 \\
\hline $\mathrm{Bi}_{2} \mathrm{WO}_{6}-\mathrm{rGO}$ & Hydrothermal method & Photodegradation of RhB & 2.04 times higher than $\mathrm{Bi}_{2} \mathrm{WO}_{6}$ & Visible & 99 \\
\hline $\mathrm{Bi}_{2} \mathrm{MoO}_{6}-\mathrm{rGO}$ & Hydrothermal method & Photodegradation of MB & $\begin{array}{l}3.67 \text { times higher than pure } \\
\mathrm{Bi}_{2} \mathrm{MoO}_{6}\end{array}$ & Visible & 126 \\
\hline $\mathrm{InNbO}_{4}-\mathrm{rGO}$ & Hydrothermal method & $\begin{array}{l}\text { Photodegradation of } \mathrm{MB} \\
\text { Photodegradation of } \\
\text { 2,4-dichlorophenol }\end{array}$ & $\begin{array}{l}1.87 \text { times higher than } \mathrm{InNbO}_{4} \\
2.10 \text { times higher than } \mathrm{InNbO}_{4}\end{array}$ & Visible & 127 \\
\hline Ag@AgCl-rGO & Solution mixing method & Photodegradation of RhB & 5.1 times higher than Ag@AgCl & Visible & 128 \\
\hline
\end{tabular}


Table 2 (Contd.)

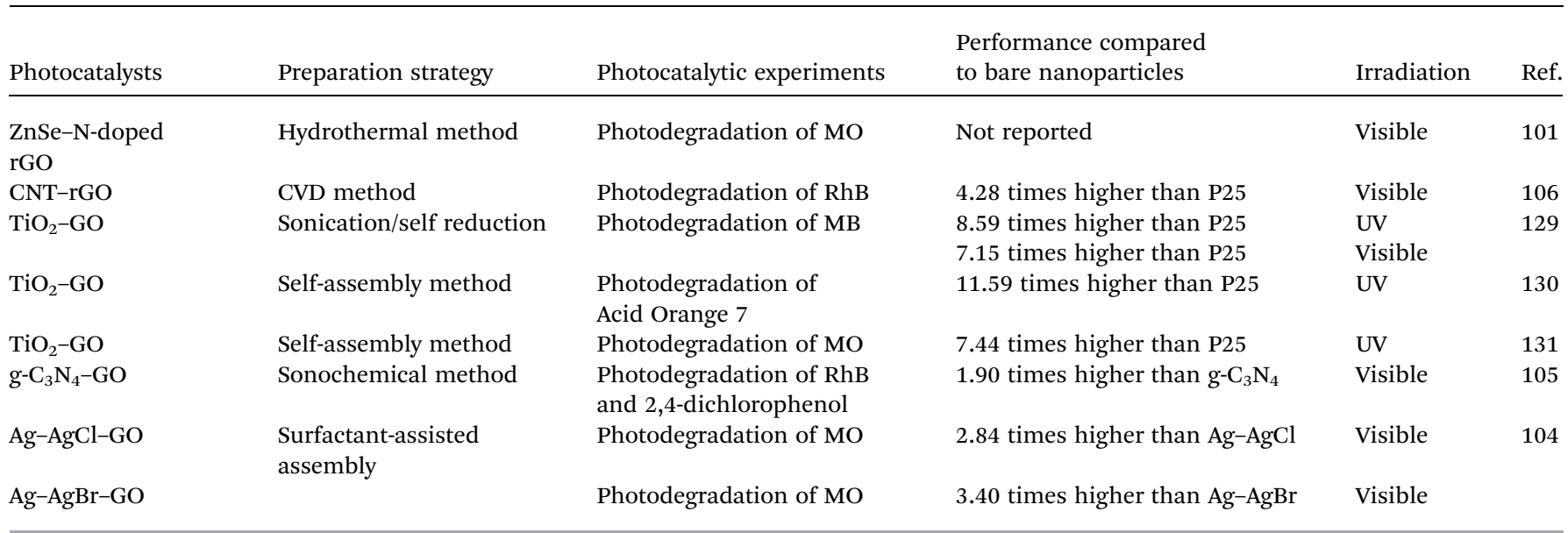

degradation of proteins in viruses, thereby leading to the efflux of virus RNA. Liu et al. have shown that a GO enwrapped $\mathrm{AgPO}_{4}$ material can be used for disinfection of E. coli. ${ }^{136}$ The material was shown to be more effective than the bare $\mathrm{AgPO}_{4}$ nanoparticles under visible radiation, while the authors conjectured that the enhancement in activity was due to adsorption of $E$. coli by GO.

Work by the Pradeep group has shown that by anchoring lactoferrin protected $\mathrm{Au}$ clusters or chitosan to GO and rGO, improved antibacterial properties are observed. ${ }^{137}$ The antibacterial properties of the material were tested using $E$. coli cell lines, with the lactoferrin protected materials showing an enhanced antibacterial performance due to a synergistic effect. Cai and co-workers have shown that a synergistic effect is likewise observed when $E$. coli and S. aureus are exposed to a brilliant blue-rGO-tetradecyltriphenylphosphonium bromide composite. ${ }^{138}$ The authors showed that the material can be used for specific targeting as it only displays mild cytotoxicity.

\section{Gas adsorption and gas phase separation}

The increase in the concentration of $\mathrm{CO}_{2}, \mathrm{CH}_{4}$ and other greenhouse gases in the atmosphere is causing anthropogenic global warming. ${ }^{139}$ What the outcomes of this increase in greenhouse gases will be is the unanswered question. ${ }^{140,141}$ Regardless, action should be taken and this requires the adsorption of these gases. Graphene, like other carbon-based materials, is light and cheap to produce in comparison to other solid state gas adsorbent materials. ${ }^{142}$ It is these properties that make the use of graphene feasible in the storage of greenhouse gases, as well as other more environmentally friendly gases. ${ }^{143}$

\subsection{Gas adsorption}

Currently there are new technologies being adapted and employed for gas adsorption in industrial settings. For example, capturing $\mathrm{CO}_{2}$ by aqueous ammonia has shown advantages over other state-of-the-art $\mathrm{CO}_{2}$-capture technology. ${ }^{144}$ On the other hand, as evidence of $\mathrm{CO}_{2}$ storage using functionalized graphene, Ramaprabhu and Mishra prepared hydrogen-induced thermally exfoliated $\mathrm{GO}$ at $200{ }^{\circ} \mathrm{C} .{ }^{145}$ By means of Fourier transform infrared spectroscopy they confirmed the physical adsorption of $\mathrm{CO}_{2}$ in $\mathrm{GO}$ (see Fig. 10). The authors reported that the maximum $\mathrm{CO}_{2}$ adsorption capacity was $21.6 \mathrm{mmol} \mathrm{g}^{-1}$ at $298 \mathrm{~K}$ and 11 bar.

Elements like nitrogen, sulfur and oxygen can increase the basic character in carbonaceous materials. This basic character provides an attractive opportunity for enhanced $\mathrm{CO}_{2}$ adsorption due to the acidic character of the gas. Keeping this in mind, different groups have synthesized basic graphene composites for $\mathrm{CO}_{2}$ adsorption. It was shown by Chandra et al. that $\mathrm{N}$-doped porous carbon could be obtained by the chemical activation of a polypyrrole-rGO composite. ${ }^{146}$ The authors then showed that this doped material could be used for effective and selective $\mathrm{CO}_{2}$ storage. The polypyrrole-rGO composite activated at $600{ }^{\circ} \mathrm{C}$ showed (Fig. 11) a maximum recyclable $\mathrm{CO}_{2}$ uptake of $4.3 \mathrm{mmol} \mathrm{g}^{-1}$ at $25^{\circ} \mathrm{C}$ and $1 \mathrm{~atm}$. This material was shown to be a highly selective adsorptive for $\mathrm{CO}_{2}$ compared to $\mathrm{N}_{2}$. Similarly, Mishra and Ramaprabhu prepared a polyaniline graphene nanocomposite for reversible $\mathrm{CO}_{2}$ capture. ${ }^{147}$ The authors

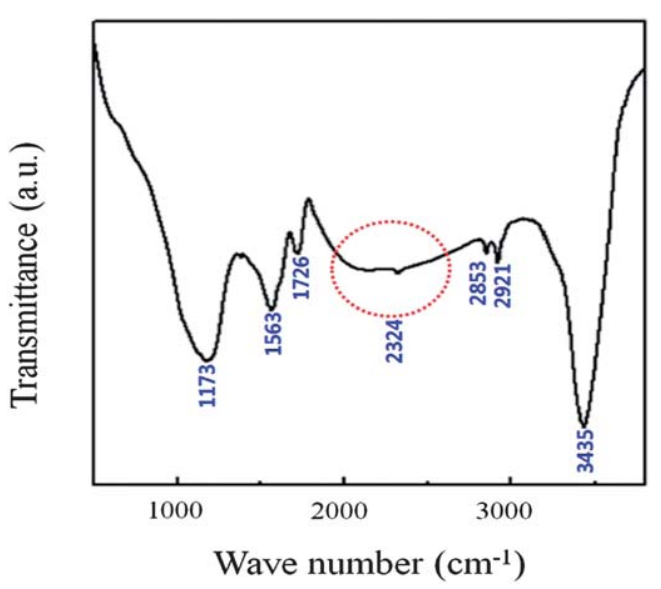

Fig. 10 Fourier transform infrared spectrum of molecular adsorption of $\mathrm{CO}_{2}$ in a GO sample. A. K. Mishra and S. Ramaprabhu, AIP AdV., 2011, 1, 032152; used in accordance with the Creative Commons Attribution 3.0 Unported License. 
a

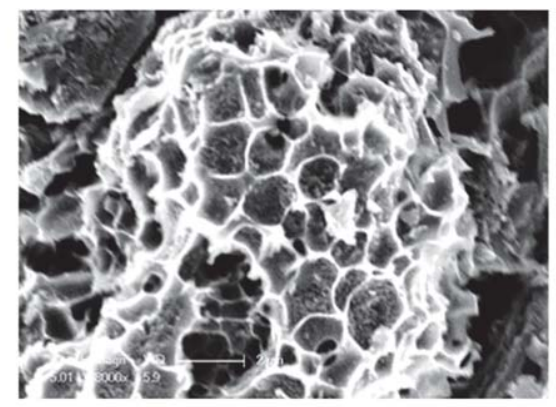

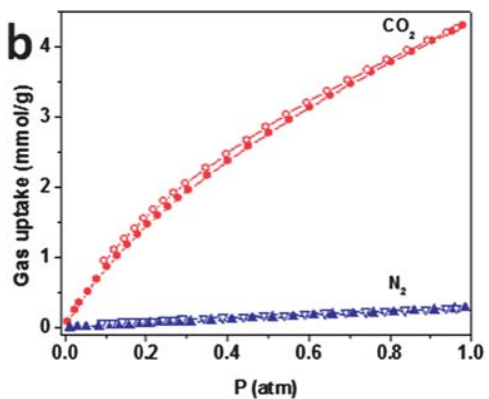

Fig. 11 (a) SEM image of the chemically activated polypyrrole-rGO composite at $600^{\circ} \mathrm{C}$ and (b) gas adsorption capacity of the sample. Reproduced from ref. 146.

showed that maximum adsorption capacities of 75,47 and $31 \mathrm{mmol} \mathrm{g}^{-1}$ can be obtained at 11 bar pressure and 25,50 and $100{ }^{\circ} \mathrm{C}$, respectively. In recycling studies a capacity $2-3 \%$ less than the initial maximum capacity was reported.

Besides elemental doping into carbon-based materials, the porosity and specific surface area of the adsorbent material can be tuned to increase the gas adsorption capacity. Srinivas and Yildirim have prepared porous graphene oxide derived carbons by chemical activation using two different methods i.e. solution phase and solid phase mixing. They showed that the samples activated at $800{ }^{\circ} \mathrm{C}$ in solution and solid phase show maximum adsorption for both $\mathrm{CH}_{4}$ and $\mathrm{CO}_{2}$ gas, suggesting that this behavior is due to the porous nature of the samples as well as high surface area. The authors showed that maximum adsorption capacities at low pressures ( 1 bar, $300 \mathrm{~K}$ ) show no difference in adsorption regardless of the activation temperature, however the maximum capacities are varied at higher pressures ( $300 \mathrm{~K}, 30$ bar and $45 \mathrm{bar}) \cdot{ }^{148}$ By exploiting the same ideas as Srinivas, it has been shown by Ning and Wei that nanomesh graphene (NMG) can be produced using a CVD process with porous $\mathrm{MgO}$ layers as a template. ${ }^{149}$ The material displayed a high specific surface area and a micropore distribution around $1 \mathrm{~nm}$, which in turn resulted in impressive volumetric storage capacities for methane $(236 \mathrm{v} / \mathrm{v}$ at $9 \mathrm{MPa})$ and carbon dioxide ( $240 \mathrm{v} / \mathrm{v}$ at $3.1 \mathrm{MPa})$, additionally the NMG material was shown to be selective for the adsorption of $\mathrm{CO}_{2}$ over $\mathrm{CH}_{4}$ and $\mathrm{H}_{2}$.

Layered double hydroxides (LDHs) have been applied as $\mathrm{CO}_{2}$ adsorbents at high temperatures. However, regeneration of these samples usually requires very high temperatures. Recently, a low temperature method for the preparation of LDH-GO hybrids by using a layer-by-layer self-assembly process of positively charged $\mathrm{Mg}-\mathrm{Al} \mathrm{LDH}$ onto negatively charged GO has been reported. ${ }^{150}$ In this process GO acts as a support that improves the nucleation of active sites which upon activation form mixed metal oxides (MMOs) i.e. the basic sites required for $\mathrm{CO}_{2}$ adsorption. It was shown that the inclusion of GO (7 wt\%) leads to an enhancement in adsorption capacity 2.5 times higher than that of the pure $\mathrm{LDH}\left(62 \%\right.$ at $573 \mathrm{~K}$ and $P\left(\mathrm{CO}_{2}\right)=$ $0.2 \mathrm{bar}$ ), as well as stability upon recycling. The enhancement in adsorption capacity is due to the dispersion/stabilization of the $\mathrm{LDH}$ on the GO support, leading to increases in active/effective LDH surface area.
Theoretical studies have shown that the potential for graphene-based materials for gas adsorption has not been reached. ${ }^{151-154}$ Wood and Pathak used DFT to determine the geometry and energetics of $\mathrm{CH}_{4}$ and $\mathrm{CO}_{2}$ adsorbed on zigzag graphene nanoribbons (ZGNRs) with attached chemical functional groups. ${ }^{151}$ The authors showed that polar groups $(\mathrm{COOH}$, $\mathrm{NH}_{2}, \mathrm{NO}_{2}$, and $\mathrm{H}_{2} \mathrm{PO}_{3}$ ) are promising candidates for enhancing $\mathrm{CO}_{2}$ and $\mathrm{CH}_{4}$ adsorption capacity by strengthening adsorption and activating exposed edges and terraces to introduce additional binding sites. This result has important implications for improving uptake in carbon structures that are known to have high quantities of edge carbons. Using molecular dynamics simulations Shan et al. have similarly shown that functionalization can be used to create porous graphene membranes which can be used to separate $\mathrm{CO}_{2}$ and $\mathrm{N}_{2}$. The authors showed that these membranes selectively filter the gas mixture by preferably adsorbing one species over the other. ${ }^{152}$

By using DFT and molecular dynamics simulations Carrillo et al. studied the adsorption of $\mathrm{CO}_{2}$ on a Ti-graphene system with high metal coverage. ${ }^{153}$ It was shown that the positive charge carrying $\mathrm{Ti}$ atoms on graphene surfaces attract

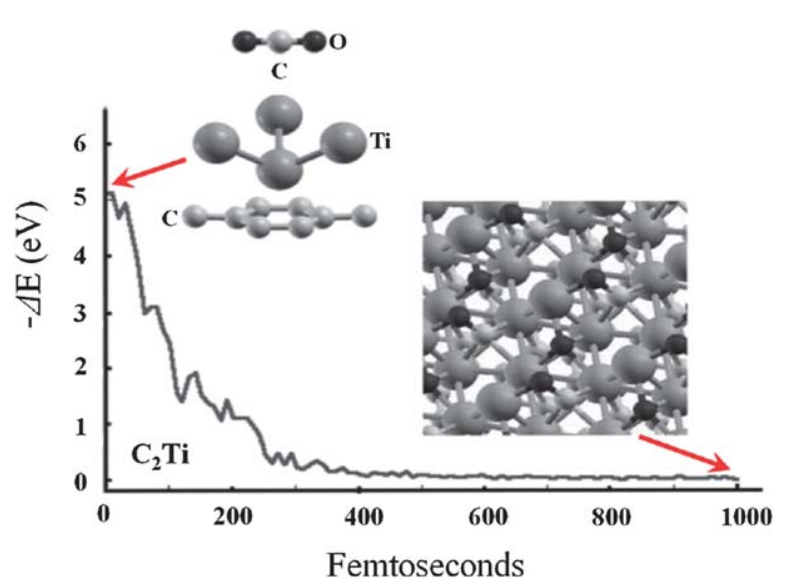

Fig. $12 \mathrm{CO}_{2}$ adsorption onto Ti-graphene $\left(\mathrm{C}_{2} \mathrm{Ti}\right)$. The final configuration shows the dissociation of the molecule in $\mathrm{CO}$ and $\mathrm{O}$. The initial orientation of the molecule has no influence on the result. Reprinted from I. Carrillo, E. Rangel and L. F. Magana, Adsorption of carbon dioxide and methane on graphene with a high titanium coverage, Carbon, 47, 2758. Copyright 2009, with permission from Elsevier. 
negatively charged oxygen atoms towards the graphene surfaces, thereby dominating the initial repulsion of the $\mathrm{C}$ atom by the $\mathrm{Ti}$ atoms. From an experimental standpoint, the strong interaction results from one $\mathrm{O}$ atom trapping an electronic charge from four Ti atoms in the upper plane (see Fig. 12), so it is essential to place mono-dispersed $\mathrm{Ti}$ atoms on the graphene surface.

Cazorla et al. showed using first-principles study that Cadecorated graphene has an unusually large $\mathrm{CO}_{2}$ uptake capacity ( 0.1 to $0.4 \mathrm{~g} \mathrm{~g}^{-1}$ ) at low pressure because of their unique topology and a strong interaction between the metal nanoparticles and $\mathrm{CO}_{2}$ molecules. ${ }^{154}$ The strength of the Ca metal and $\mathrm{CO}_{2}$ molecule interactions can be efficiently tuned as a function of the Ca loading content (Table 3).

In attempts to optimize the nanoarchitecture of carbonbased materials for hydrogen storage, Srinivas and colleagues have shown that rGO nanosheets derived from hydrazine reduction of GO possess many wrinkles and form an aggregated structure that can store $\mathrm{H}_{2}$. The rGO material with a surface area of $640 \mathrm{~m}^{2} \mathrm{~g}^{-1}$ exhibited a hydrogen adsorption capacity of $1.2 \mathrm{wt}$ $\%$ at $77 \mathrm{~K}$ and $0.1 \mathrm{wt} \%$ at $298 \mathrm{~K} \cdot{ }^{155}$ Recently, Guo et al. have shown that a hierarchical rGO material with a surface area of $1305 \mathrm{~m}^{2} \mathrm{~g}^{-1}$ is capable of storing $4 \mathrm{wt} \%$ of hydrogen at $77 \mathrm{~K}$ and 1 bar. ${ }^{\mathbf{1 5 6}}$ The storage capacity of the material is believed to be due to the nanoporous structure as well as the high surface area, although the authors suggest that defect sites may play an important role as well.

Theoretical predictions show that the weak binding energy of molecular hydrogen on the carbon surface results in a low storage capacity under ambient conditions. ${ }^{157,158}$ By calculations of graphene buckling, convex regions in corrugated graphene are energetically favorable for hydrogen binding. ${ }^{159}$ A corrugated graphene multilayer system can reversibly store hydrogen with a maximum capacity of $8 \mathrm{wt} \%$ under ambient conditions by controlling the local curvature. However, these values are still much smaller than those reported by other materials. For example, ammonia borane $\left(\mathrm{NH}_{3} \mathrm{BH}_{3}\right)$ shows a high potential $\mathrm{H}_{2}$ capacity of $19.6 \%$ at low releasing temperatures. Group I and II metal amidoboranes have been identified as one of the promising families of materials for efficient $\mathrm{H}_{2}$ storage. ${ }^{\mathbf{1 6 0 , 1 6 1}}$

Recently, Lee et al. have reported the theoretical energetics of the $\mathrm{H}_{2}$-binding by neutral and multiply charged titanium as well as other transition metals, concluding that the neutral $\mathrm{Ti}-\mathrm{H}_{2}$ system has a dihydride structure with covalent interactions, while the charged systems have dihydrogen structures with noncovalent interactions. ${ }^{\mathbf{1 6 2}}$ Wang et al. demonstrated theoretically that Ti atoms can be strongly anchored to the oxygen sites of GO, which prevents clustering of Ti atoms. ${ }^{163}$ It was shown that the high binding energy of Ti to several $\mathrm{H}_{2}$ molecules $\left(14-41 \mathrm{~kJ} \mathrm{~mol}^{-1}\right.$ $\mathrm{H}_{2}$ ) can enable the formulated Ti-dispersed GO to capture $4.9 \mathrm{wt}$ $\% \mathrm{H}_{2}$. The hydrogen storage of this Ca-decorated zigzag graphene nanoribbon was calculated to be $5 \mathrm{wt} \%$ under ambient conditions. ${ }^{164}$ Hussain and co-workers reported in a related theoretical study that a Ca-doped graphane sample (11.11\% Ca doping) could achieve $6 \mathrm{wt} \% \mathrm{H}_{2}$ uptake. ${ }^{165}$ Theoretical predictions have shown that in Li-decorated graphene, hydrogen uptake can be increased to $12 \mathrm{wt} \%$ due to the induced electric field created by $\mathrm{Li}$ covered graphene. ${ }^{\mathbf{1 6 6}}$ In addition, a model calculation on welldesigned porous graphene decorated with $\mathrm{Li}$ is shown to be potentially capable of adsorbing hydrogen up to $12 \mathrm{wt} \% .^{167}$

Besides the physisorption of hydrogen on carbon surfaces, the incorporation of hydrogen into framework structures is another promising method to store hydrogen gas. In a sandwich model of graphene nanosheets, layers of hydrogen molecules can be accommodated in the space between the graphene nanosheets. According to this model a monolayer of hydrogen yielding $2-3 \mathrm{wt} \%$ at $5 \mathrm{MPa}$ is predicted to be stored in graphene layers separated by a spacing of $6 \AA{ }^{168}$ Recently, it has been shown that the interlayer distance in multilayered GO can be modulated by thermal annealing, ${ }^{\mathbf{1 6 9}}$ reporting that a maximum hydrogen capacity of $4.8 \mathrm{wt} \%$ at $77 \mathrm{~K}$ and at $9.0 \mathrm{MPa}$ could be obtained when the interlayer distance is $6.5 \AA$. Calculations have shown that a GO framework (GOF) which can be prepared from GO and benzenediboronic acid could be used for hydrogen adsorption (Fig. 13b), ${ }^{\mathbf{1 7 0 , 1 7 1}}$ predicting that the GOF can theoretically achieve $6.1 \mathrm{wt} \% \mathrm{H}_{2}$ uptake at $77 \mathrm{~K}$ and 1 bar. However, the experimental studies only showed a maximum uptake of $1 \mathrm{wt}$ $\%{ }^{170}$ In a similar study Srinivas et al. used solvothermal reactions to prepare a porous GOF. ${ }^{\mathbf{1 7 2}}$ The obtained framework pillared by 1,4-phenyldiboronic acid had a maximum adsorption capacity of $1.2 \mathrm{wt} \%$ at $77 \mathrm{~K}$ and $10 \mathrm{bar}$. The limit of experimental hydrogen storage in the frameworks is due to their surface area being much lower than the theoretically predicted value for pristine graphene.

Table 3 Binding energy per $\mathrm{CO}_{2}$ molecule and corresponding gas-adsorption capacities of Ca-decorated graphene and CNTs as a function of Ca concentration $X_{\mathrm{Ca}}{ }^{a}{ }^{a}$ Reprinted with permission from C. Cazorla, S. A. Shevlin and Z. X. Guo, J. Phys. Chem. C, 2011, 115, 10990. Copyright 2011 American Chemical Society

\begin{tabular}{|c|c|c|c|c|c|c|}
\hline$X_{\mathrm{Ca}} \%$ & \multicolumn{2}{|c|}{ Graphene } & \multicolumn{2}{|c|}{$\mathrm{CNT}(10,0) R=3.96 \AA$} & \multicolumn{2}{|c|}{$\operatorname{CNT}(6,0) R=2.42 \AA$} \\
\hline $0.0<X_{\mathrm{Ca}} \leq 5.0$ & -1.022 & 0.134 & -1.865 & 0.085 & -1.235 & 0.134 \\
\hline $5.0<X_{\mathrm{Ca}} \leq 15.0$ & -2.731 & 0.323 & -1.902 & 0.275 & -1.543 & 0.239 \\
\hline $15.0<X_{\mathrm{Ca}} \leq 20.0$ & -0.101 & 0.392 & -2.283 & 0.440 & -1.646 & 0.392 \\
\hline
\end{tabular}

${ }^{a}$ First-row results were obtained for pristine nanostructures and last-row results for equilibrium Ca-decorated nanostructure geometries. Binding energies and carbon-uptake capacities are expressed in units of eV per molecule and $\mathrm{g}^{\mathrm{CO}_{2}}$ per $\mathrm{g}$ sorbent, respectively. 
(1)

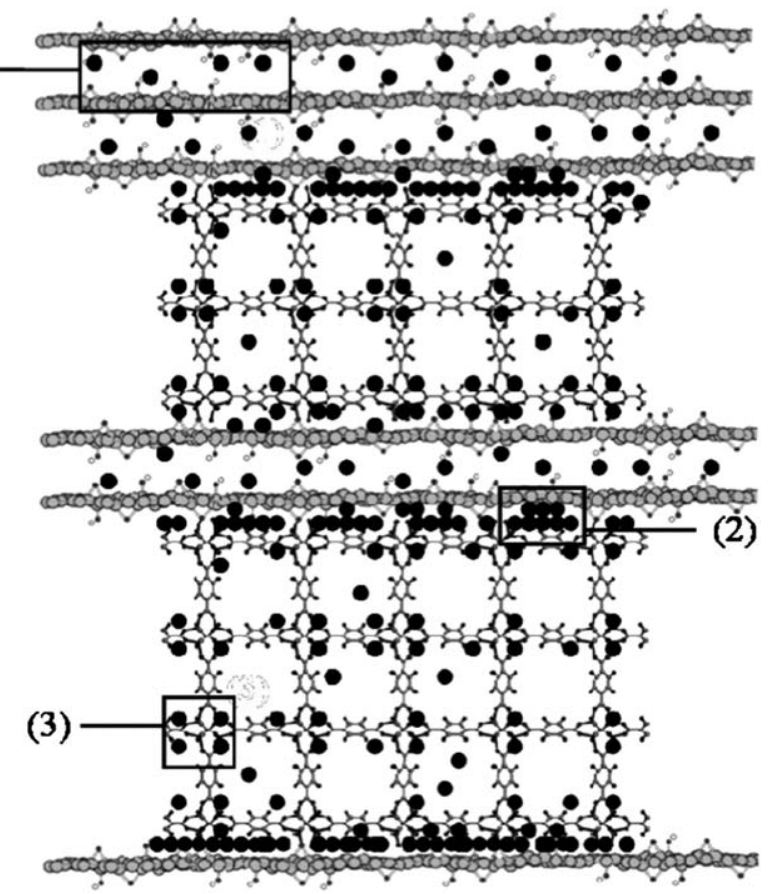

Fig. 13 Schematic representation of the mechanisms of ammonia (black circle) adsorption in the composites including: (1) intercalation between the graphene layers, (2) adsorption at the interface between the graphene layers and the MOF5 segments, (3) hydrogen bonding with the oxygen atoms of zinc oxide in MOF-5. Copyright 2010 Wiley. Used with permission from C. Petit and T. J. Bandosz, Enhanced adsorption of ammonia on metal-organic framework/graphite oxide composites: analysis of surface interactions, Adv. Funct. Mater., Wiley.

The group of Froudakis has shown that instead of pillaring graphene sheets with organic molecules, a 3D network nanostructure of graphene and carbon nanotubes could be used for hydrogen storage. ${ }^{173,174}$ They showed that by doping the framework with $\mathrm{Li}^{+}$cations, the structure can potentially achieve a hydrogen capacity of more than $10 \mathrm{wt} \%$ at $77 \mathrm{~K}$ and $100 \mathrm{bar}$, satisfying the requirement of DOE for mobile applications. ${ }^{174}$ Recently, a 3D pillared structure of GO and carbon nanotubes has been experimentally fabricated by utilizing the liquid crystalline properties of $\mathrm{GO}$ in aqueous media to construct the ordered architecture. The material synthesized showed a hydrogen storage performance of $2.6 \mathrm{wt} \%$ at $50 \mathrm{bar}$ and $298 \mathrm{~K} .{ }^{175}$

\subsection{Reactive gas adsorption}

As has been shown in Section 3.1, graphene-based materials can be utilized as adsorbents for gas storage. However, due to the variety of functional groups in chemically derived rGO, chemical bond formation can occur between functionalities and some types of gas molecules during the adsorption process.

Theoretical evidence for reactive gas adsorption has been provided by Tang and Cao, who showed using density functional theory that GO is a better adsorbent than graphene for $\mathrm{NO}_{x}(x=1,2,3)$ and $\mathrm{N}_{2} \mathrm{O}_{4} \cdot{ }^{176}$ In their study, they showed that the defect sites in GO (i.e. carbonyl and hydroxyl) increase the binding energies of the nitrogen oxides as well as enhancing the charge transfer from the nitrogen oxides which in turn leads to chemisorption. In another study the authors have similarly shown how $\mathrm{NH}_{3}$ can bind to the functional groups (i.e. hydroxyl and epoxy) of the graphene oxide surface, thereby forming $\mathrm{NH}_{2}$ or NH groups. In this study, the authors showed that the hydroxyl groups are more reactive than the epoxy group towards chemical binding with $\mathrm{NH}_{3}$, however this result contradicts the current experimental evidence. ${ }^{177-179}$ Additionally, it was shown that the desorption and adsorption of ammonia on the surface can lead to removal of the oxygen functionalities i.e. reduction of graphene oxide using $\mathrm{NH}_{4} \mathrm{OH} .{ }^{180} \mathrm{~A}$ DFT study by Liu et al. has shown that graphite defect sites can react with $\mathrm{CH}_{4}{ }^{181}$ This study showed that a methane molecule is activated at certain monovacancy sites on the graphite surface. This activation then leads to chemisorption occurring as the methane $\left(\mathrm{CH}_{4}\right)$ ruptures into $\mathrm{CH}_{2}$ and $2 \mathrm{H}$ which then chemisorb at the vacancy site.

In theoretical studies of metal nanoparticle GO materials, Wang and Zhang used first-principles calculations to show that Ti-decorated GO should act as an ideal sorbent for CO separation from gas mixtures as Ti-GO exhibits a large binding energy of $70 \mathrm{~kJ} \mathrm{~mol}^{-1}$ for $\mathrm{CO}$ molecules compared to other gases $\left(\mathrm{N}_{2}\right.$, $\left.\mathrm{CH}_{4}, \mathrm{CO}_{2}\right)^{182}$ In another study An et al. have shown that the incorporation of $\mathrm{WO}_{3}$ nanorods on a graphene substrate can be used for high-efficiency visible-light-driven photocatalysis, as well as $\mathrm{NO}_{2}$ gas sensing. ${ }^{118}$ It is believed upon adsorption of the $\mathrm{NO}_{2}$ gas on the $\mathrm{WO}_{3}$ nanorods that there is an increase in the thickness of the depletion layer. This increase in the depletion layer thickness translates into an increased resistance and thus an improved sensing ability.

The majority of experimental research conducted on reactive gas adsorption in graphene-based materials has been reported by the Bandosz group. The group has shown that $\mathrm{SO}_{2}, \mathrm{H}_{2} \mathrm{~S}, \mathrm{NO}_{2}$ and $\mathrm{NH}_{3}$ can be reactively adsorbed on graphene modified surfaces. Studies by this group have shown that $\mathrm{NH}_{3}$ gas can be effectively captured by modifying the graphite oxide with either a aluminium-zirconium polycation, ${ }^{183} \mathrm{Al}_{13}$ polycations ${ }^{184}$ or $\mathrm{MnO}_{2}$ nanoparticles. ${ }^{185}$ An initial study revealed that when using a hydroxyaluminium-zirconium polycation surfactant that dispersed graphene layers stack again with the retention of space between the layers. ${ }^{183}$ This restacking allows $\mathrm{NH}_{3}$ to penetrate the structure and react with the $\mathrm{Al} / \mathrm{Zr}$ Bronsted acidic centers, thereby forming a very stable bond. This result is similar to the result obtained using the $\mathrm{Al}_{13}$ polycations, however in both studies it was noted that water plays a major role in the adsorption process as it is able to compete for binding places with the ammonia.

In further studies they showed that surface properties such as surface chemistry, ${ }^{177-179}$ or textural properties ${ }^{177,179}$ can change the $\mathrm{NH}_{3}$ adsorption properties of the material. These studies showed that functional groups are a necessity for $\mathrm{NH}_{3}$ adsorption on graphite oxide. The interlayer distance between individual sheets can increase adsorption, while pore size does not play a big role in adsorption. Of the functional groups necessary for effective adsorption of $\mathrm{NH}_{3}$, it was shown that epoxides are the most important group. This is a very important result as the synthetic method employed in manufacturing graphene oxide can affect the surface chemistry. Interestingly, 
they showed that water can have either a positive effect or negative effect on the adsorption capacity depending on the content, i.e. it can enhance the formation of ammonium ions, but at the same time it blocks access to functional groups.

Composite MOF and graphite oxide materials should offer high gas adsorption capacities, as they take advantage of both MOF and graphite oxide reactive sites. These composite materials have been synthesized and studied by the Bandosz group and the reports have highlighted some important features of these systems. In an initial study by Petit et al. MOF-5 and GO composites were prepared and employed as $\mathrm{NH}_{3}$ absorbents under dry conditions. ${ }^{\mathbf{1 8 6}}$ It was found that the adsorption capacity of the composites is synergetic, with a higher GO content leading to a higher adsorption capacity. This synergetic effect is believed to be due to the development of significant pore volume in the composite material due to enhanced dispersive forces between the two constituents, see Fig. 13.

To improve the adsorption of small molecules such as $\mathrm{NH}_{3}$ and hydrogen, MOF-GO hybrid materials were synthesized using Zn-based MOF-5 and Cu-based MOF HKUST-1. ${ }^{187}$ These MOFs were chosen as they should enhance the dispersive forces of the MOFs in the composite material. The copper-based material showed greater adsorption than the zinc-based materials, due to the presence of unsaturated metallic sites in the HKUST-1. It was shown that $\mathrm{NH}_{3}$ adsorption causes a collapse of the MOF in both materials, this is because $\mathrm{NH}_{3}$ interacts with the metallic centers of the MOFs either by hydrogen bonding (zinc-based materials) or coordination and subsequent complexation (copper-based materials). ${ }^{187,188}$

In another study the group has shown that there are limits to the $\mathrm{NH}_{3}$ adsorption capacity when MOF-GO composite materials are used. ${ }^{189}$ In this study a GO and MIL-100(Fe) composite was synthesized; however, this material does not display a high adsorption capacity as the MIL-100(Fe) is composed of spherical cages (unlike MOF-5 and HKSUT-1). This difference in geometry results in a larger amount of GO attaching to the individual spherical cages, which in turn inhibits the formation of the MIL-100(Fe) structure. These factors result in the composite with the highest GO content having the lowest porosity, which translates to a smaller $\mathrm{NH}_{3}$ adsorption capacity than for a physical mixture of MIL-100(Fe) and GO.

Besides $\mathrm{NH}_{3}$, other gases such as $\mathrm{H}_{2} \mathrm{~S}, \mathrm{NO}_{2}$ and $\mathrm{SO}_{2}$ have been reactively adsorbed using graphene-based materials. It has been shown by the Bandosz group that $\mathrm{N}$-doped graphite oxide, formed by the reduction of graphite oxide using $\mathrm{NH}_{3}$ gas, can be used to capture $\mathrm{H}_{2} \mathrm{~S}$ gas. ${ }^{190}$ It was shown that the basic nature of nitrogen tends to enhance the dissociation of acidic hydrogen sulfide and attracts $\mathrm{HS}^{-}$ions via electrostatic interactions. These ions are then subsequently oxidized to elemental sulfur and a small amount of $\mathrm{SO}_{2}$.

In three separate studies it was shown that composite materials of GO or graphene and $\mathrm{Zn}$ oxy(hydroxide), $\mathrm{Zr}(\mathrm{OH})_{4}$, copper (hydr)oxychlorides or cobalt hydr(oxide) were shown to be effective materials for $\mathrm{H}_{2} \mathrm{~S}$ removal in the gas phase. ${ }^{191-194}$ When the GO and $\mathrm{Zn}$ oxy(hydroxide) or $\mathrm{Zr}(\mathrm{OH})_{4}$ materials were employed in $\mathrm{H}_{2} \mathrm{~S}$ removal they both proved to be highly effective, however both of these materials form noxious $\mathrm{SO}_{2}$ gas as a byproduct of the $\mathrm{H}_{2} \mathrm{~S}$ decomposition reaction. ${ }^{191,192}$ An example of the reaction mechanism involved in the decomposition of $\mathrm{H}_{2} \mathrm{~S}$ using $\mathrm{Zn}(\mathrm{OH})_{2}$ is shown in Fig. 14. However, the GO-graphene and copper (hydr)oxychlorides or cobalt hydr(oxide) composite showed no evolution of $\mathrm{SO}_{2}$ during the reactive adsorption of $\mathrm{H}_{2} \mathrm{~S} .{ }^{193,194}$ The reason that no $\mathrm{SO}_{2}$ forms when using these composites is believed to be due to a lower oxidation activity by the composite and/or a greater ability to retain $\mathrm{SO}_{2}$ on the surfaces of these materials. For all of the metal hydroxide $\mathrm{GO}$ materials used in $\mathrm{H}_{2} \mathrm{~S}$ adsorption it was found that water in the samples increases the adsorption capacity. This is believed to be due to the acidic $\mathrm{H}_{2} \mathrm{~S}$ gas reacting to form $\mathrm{HS}^{-}$which is far more reactive towards functional groups. From these studies, it can be seen that a complete mechanistic understanding of the reaction processes involved is essential for effective pollution management.

As for $\mathrm{NH}_{3}$ gas removal, MOF-GO composite materials have been employed to remove $\mathrm{H}_{2} \mathrm{~S}$ and $\mathrm{NO}_{2}$ gas. ${ }^{195-198}$ When one considers the removal of $\mathrm{H}_{2} \mathrm{~S}$ or $\mathrm{NO}_{2}$ using a GO and HKUST-1 composite, it is observed that both physisorption and chemisorption play a role. ${ }^{\mathbf{1 9 5 , 1 9 6 , 1 9 9}}$ The physical adsorption is characterized by adsorption in the pore spaces created by dispersive forces at the interfaces between the MOF units and the graphene layers. The chemical adsorption between the $\mathrm{NO}_{2}$ and $\mathrm{H}_{2} \mathrm{~S}$ gas and the composite occurs at the unsaturated $\mathrm{Cu}$ sites of the MOF, resulting in the formation of copper sulfide and nitrate as well as a change in coordination between the $\mathrm{Cu}$ and BTC ligand (see Fig. 15). These changes result in collapse of the MOF structure and permanent loss of porosity. However this loss of structure makes more $\mathrm{Cu}$ sites available for adsorption, so the potential for acidic gas adsorption is increased. As was noted for the $\mathrm{NH}_{3}$ adsorption in these materials, the presence of water enhances the uptake of the acidic gases due to dissolution.

The same group has also shown that an iron acetato GO composite can be employed in $\mathrm{NO}_{2}$ adsorption. ${ }^{197}$ In this study the authors showed that $\mathrm{NO}_{2}$ is reactively adsorbed on the surface of the iron acetato material, whereafter it is reduced to NO. Importantly, the release of NO can be counteracted by the inclusion of active iron species, i.e. $\gamma-\mathrm{FeOOH}$ and $\alpha-\mathrm{Fe}_{2} \mathrm{O}_{3}$, which also results in a greater adsorption capacity. However, even with the inclusion of these reactive iron centers the

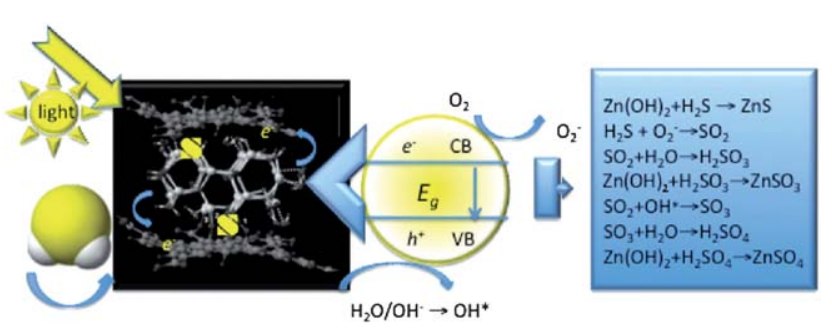

Fig. 14 Schematic representation of surface processes involved in the reactive adsorption of $\mathrm{H}_{2} \mathrm{~S}$ using a GO Zn oxy(hydroxide) composite. Reprinted with permission from M. Seredych, O. Mabayoje and T. J. Bandosz, Langmuir, 2012, 28, 1337. Copyright 2012 American Chemical Society. 


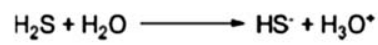

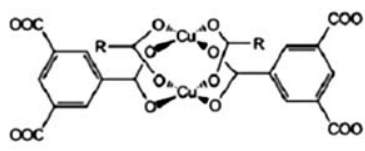

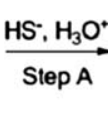

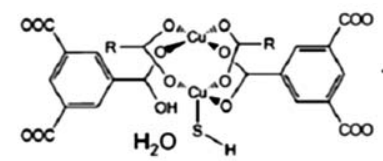

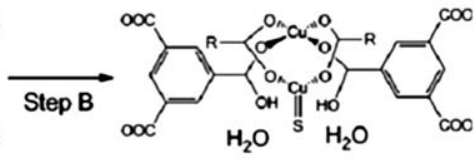

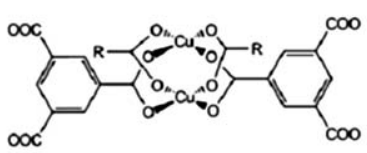

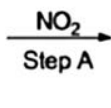

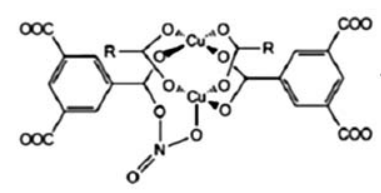

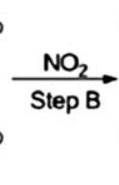

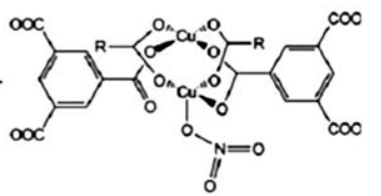<smiles>O=C(O)c1cc(Br)cc(C(=O)O)c1</smiles>

+ NO

Fig. 15 Proposed reaction pathways for the $\mathrm{H}_{2} \mathrm{~S}$ (top) and $\mathrm{NO}_{2}$ (bottom) adsorption on HKUST-1 and the composite. Reprinted from A. Petit, B. Levasseur, B. Mendoza and T. J. Bandosz, Reactive adsorption of acidic gases on MOF/graphite oxide composites, Microporous Mesoporous Mater., 107, 154. Copyright (2012), with permission from Elsevier.

synthesized materials still showed NO release during the chemical conversion of $\mathrm{NO}_{2}$.

The adsorption of $\mathrm{SO}_{2}$ has been achieved using a hydrous zirconia-graphene composite, where the composite material adopts a $\mathrm{Zr}(\mathrm{OH})_{4}$ bridged graphene layer structure. ${ }^{200}$ The interactions between the zirconia and the graphene result in pores which increase the adsorption capacity of $\mathrm{SO}_{2}$ under both dry and moist conditions compared to GO and pure $\mathrm{Zr}(\mathrm{OH})_{4}$, when the GO content is $5 \mathrm{wt} \%$. When the GO content is increased there is an increased pore formation due to enhanced binding between $\mathrm{GO}$ and $\operatorname{Zr}(\mathrm{OH})_{4}$. This leads to a higher adsorption capacity under moist conditions, as dissolution processes can occur in the increased number of pores present in these structures.

Metal clusters can act as active catalysts to dissociate hydrogen molecules into atomic hydrogen and then transport them onto a carbon support in the hydrogen spillover process, this leads to the enhancement of hydrogen uptake at operational temperatures. ${ }^{\mathbf{2 0 1 , 2 0 2}}$ The process is thermodynamically unfavorable on pristine graphene; however, hydrogenated domains in graphene improve $\mathrm{C}-\mathrm{H}$ binding to make hydrogen spillover more energetically favorable. ${ }^{202}$ Additionally, $\mathrm{Wu}$ and colleagues have demonstrated that B-doped graphene can be used to reduce the activation energy of hydrogen migration and diffusion on the substrate. ${ }^{203}$ Parambhath et al. showed experimentally that hydrogen-exfoliated graphene functionalized with Pd nanoparticles can be used for hydrogen storage (Fig. 16). ${ }^{204}$ The Pd-dispersed graphene showed a hydrogen storage capacity of $1.76 \mathrm{wt} \%$ at $298 \mathrm{~K}$ and $2 \mathrm{MPa}$. It is believed that this is due to the hydrogen spillover effect as the capacity is three times higher than that of pristine hydrogen-exfoliated graphene. In a similar way, Huang and colleagues have used both Pt and Pd as hydrogen dissociation catalysts for hydrogen storage on graphene. ${ }^{205}$ It is important to note that the two studies of Huang and Parambhath showed different hydrogen storage capacity for Pd decorated rGO samples at similar
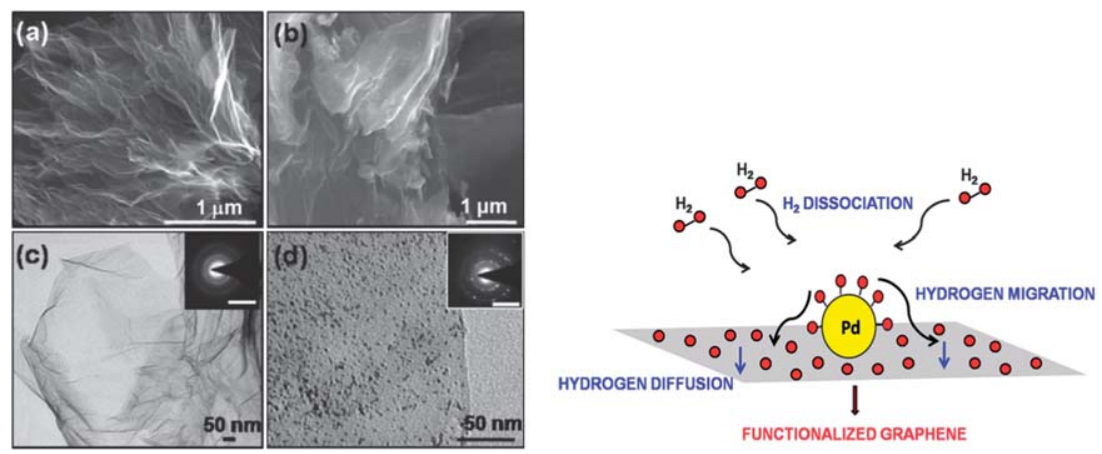

Fig. 16 FESEM image of (a) HEG and (b) Pd/f-HEG. TEM image of (c) HEG and (d) Pd/f-HEG. Inset images of parts (c) and (d) show the diffraction pattern of HEG and $\mathrm{Pd} / \mathrm{f}-\mathrm{HEG}$, respectively. The scale bars correspond to $5 \mathrm{~nm}^{-1}$. Schematic diagram of the spillover mechanism in Pd/f-HEG. Reprinted with permission from V. B. Parambhath, R. Nagar, K. Sethupathi and S. Ramaprabhu, J. Phys. Chem. C, 2011, 115, 15679. Copyright 2011 American Chemical Society. 
temperatures and pressures. In a related study Wang et al. have prepared Ni-B nanoalloys as an effective catalyst to facilitate the hydrogen spillover effect. ${ }^{206,207}$ The nanohybrid of graphene and Ni-B alloy exhibited a storage capacity of $4.4 \mathrm{wt} \%$ at $77 \mathrm{~K}$ and $106 \mathrm{kPa}$, triple the uptake of graphene without the catalyst.

\subsection{Gas phase separation}

Gas separation and purification are important industrial concerns which need to be studied further for application in clean energy. Membranes are an ideal material for separation of component gases, as efficient separation is achieved without any phase change and they also have a cheaper energy cost compared to other materials. ${ }^{208}$ Graphene displays properties that would make it an ideal substance for gas phase separation viz. atomic thickness, ${ }^{209}$ high mechanical strength, ${ }^{210}$ relative inertness and impermeability to all standard gases. ${ }^{\text {211-213 }}$

Fischbein and Drndic showed that porous graphene could be manufactured by using a focused electron beam aimed at a suspended graphene sheet. Importantly, in this work they showed that the pores created are very stable. ${ }^{\mathbf{2 1 4}}$ Theoretical studies by Jiang et al. elaborated on the use of porous graphene, in their study they showed that nitrogen functionalized pores are able to separate a $\mathrm{H}_{2}$ and $\mathrm{CH}_{4}$ gas mixture. ${ }^{215}$ In another study Du et al. showed that by altering the pore size/shape in the graphene membranes, efficient separation of a $\mathrm{H}_{2}-\mathrm{N}_{2}$ mixture could be achieved. ${ }^{216}$

Experimentally Koenig et al. have shown that porous graphene membranes, manufactured using an ultraviolet-induced oxidative etching method, can be used as molecular sieves. ${ }^{\mathbf{2 1 7}}$ Utilizing mechanical resonance and a pressurized blister test, they were able to show the leak rates of various gases $\left(\mathrm{H}_{2}, \mathrm{CO}_{2}\right.$, $\mathrm{Ar}, \mathrm{N}_{2}, \mathrm{CH}_{4}$ and $\mathrm{SF}_{6}$ ) through a porous graphene membrane. Remarkably, the results obtained by Koenig and co-workers are consistent with theoretical studies presented by other groups. ${ }^{215,218}$ Even though these studies were conducted using single gases and not gas mixtures, the results show that graphene membranes show potential for future application.

A theoretical study by Hankel et al. has shown that asymmetrically decorated/doped porous graphene membranes could potentially be used for the separation of hydrogen isotopes. ${ }^{219}$ This study takes advantage of the quantum sieving effect, with nitrogen functionalized porous graphene showing a very high selectivity for molecular deuterium over hydrogen at low temperatures. The authors also showed that by doping one side of the graphene sheet with either lithium or titanium, an asymmetric low-energy pathway through the membrane can be achieved. In a related study Hauser and Schwerdtfeger showed that nanoporous functionalized graphene membranes can be used to separate ${ }^{3} \mathrm{He}$ and ${ }^{4} \mathrm{He}$ isotopes efficiently. ${ }^{220}$ This method of separation relies on the differences in quantum tunneling probabilities by the isotopes through a designed potential well. From their calculations, the authors showed that a nitrogen-doped graphene (two-ring) pore creates a suitable potential well capable of separating the isotopes. Another study by Hauser and Schwerdtfeger has shown that functionalized graphene nanopores can be used to efficiently separate methane from air. Using density functional theory, the authors showed that graphene pores (two-ring) are promising candidates for the separation of methane from other gases including nitrogen. ${ }^{221}$

Various other theoretical studies have elaborated on the use of graphene porous membranes in gas phase separation. ${ }^{152,222-225}$ These studies focus on the functionalization of the pores and/or changing the pore size to enhance the gas phase separation efficiency, as such synthetic methods that can produce these nanostructures are very important. An interesting theoretical study by Brockway and Schrier has shown that a graphene membrane model based on a previously synthesized graphene porous membrane can be used to separate He from natural gas. 226,227 The authors conclude that the porous graphene $(E)$-stilbene 1 material outperforms existing materials in terms of selectivity and permeance.

\section{Environmental and biological toxicity of graphene}

The environmental and biological toxicity of graphene is immensely important, when one considers its use in environmental remediation and biomedical applications. Multiple recent studies have focused on the use of graphene and graphene composites in biomedical applications. ${ }^{133,228-231}$ From these studies, as well as other cytotoxicity studies on graphene and related compounds, ${ }^{69,232-251}$ we are able to draw some conclusions regarding graphene's biological toxicity.

With respect to antibacterial studies using reduced graphene oxide and graphene oxide, Akhavan et al. and $\mathrm{Hu}$ et al. have reported that the bacterial toxicity of these materials may find future application in antimicrobial products. ${ }^{133,232}$ Akhavan et al. showed that the bacterial inactivation was caused by direct contact of the bacteria with the extremely sharp edges of the nanosheets which results in cell membrane damage. This mechanism of bacterial inactivation therefore allows $E$. coli to be more resistant to graphene materials compared to $S$. aureus, due to its outer cell membrane. Liu et al. have extended this work by showing that the anti-bacterial properties of graphene depend heavily on the functional groups. ${ }^{233}$ In their work they showed that graphene oxide and reduced graphene oxide are less harmful to $E$. coli cells than graphite oxide and graphite.

However, other groups have reported the exact opposite regarding the toxicity of graphene and graphene oxide towards bacteria. These studies have shown the use of graphene in microbial fuel cells, ${ }^{249}$ graphene as a scaffold for bacterial growth, ${ }^{228}$ as well as the use of bacteria as a graphene oxide reducing agent. ${ }^{250,251}$

Various in vitro toxicity studies have been conducted to determine the toxicity of graphene towards cancer ${ }^{234-238}$ and human cell lines. ${ }^{229,239}$ The cytotoxicity towards the cancer cell lines A549 was shown to depend largely on the cell culture medium components. ${ }^{\mathbf{2 3 4 , 2 3 5}}$ In particular it was noted that fetal bovine serum played a very important role, as it seems to coat the graphene sheets making them less toxic towards cell lines. ${ }^{235}$ In a study by Gollavelli and Ling, the effect of graphene oxide and polyacrylic acid, fluorescein $o$-methacrylate 
functionalized graphene oxide, on HeLa cells was determined. ${ }^{236}$ In this study it was shown that at low concentrations the graphene materials exhibit no noticeable cytotoxicity, however at concentrations above $40 \mu \mathrm{g} \mathrm{mol}^{-1}$ oxidative stress affects cell growth. In another study the cytotoxicity of GO functionalized for photothermal therapy was tested prior to irradiation. ${ }^{238}$ In this study the authors showed that the GO material displays negligible cytotoxicity towards U87MG human glioblastoma cells at concentrations under $80 \mathrm{mg} \mathrm{mL}^{-1}$.

With respect to human cell lines, Agarwal et al. have shown that reduced graphene oxide displays no toxicity towards both oligodendroglia and fetal osteoblast cell lines. ${ }^{239}$ The authors showed the benefit of using reduced graphene oxide over SWNTs, which displayed an inhibition effect in the growth of the human cell lines. Liao and co-workers have shown that graphene oxide displays minimal cytotoxicity towards human erythrocytes and skin fibroblast cells, however graphite oxide and reduced graphene oxide were shown to inhibit cell growth. ${ }^{229}$ These results agree well with the anti-bacterial properties observed for certain graphene materials. Additionally, cytotoxicities of graphene and graphene-based materials have also been tested in mice cell lines and have been shown to have negligible toxicity at low concentrations. ${ }^{239,240}$ Interestingly, similar low concentrations have been linked to cytotoxic effects when using other carbon-based materials like CNTs. ${ }^{240-242}$

The negligible toxicity of graphene towards cell lines has resulted in various research groups using graphene-based materials as scaffolds for cell growth. Li et al. showed that mice hippocampal neurons could be grown on CVD graphene, with the scaffold even promoting neutrite growth. ${ }^{230}$ Additional studies have shown that graphene can also be used as a scaffold for human colorectal adenocarcinoma HT-29 cells ${ }^{251}$ and human stem cells. ${ }^{229,231}$

Mammalian in vivo studies of the toxicity of graphene compounds have been conducted in mice. ${ }^{\mathbf{2 4 3 - 2 4 5}}$ In a report by Zhan et al. they showed that graphene oxide displays negligible pathological toxicity in most organs, however toxicity in the lungs was observed due to the accumulation and slow clearance of the graphene oxide in the body. ${ }^{243}$ It should be noted that the pathological toxicity in the lungs only occurred with large concentrations i.e. $10 \mathrm{mg} \mathrm{kg}^{-1}$. In a separate study Duch and co-workers noted that the toxicity of graphene materials to mice lung cells could be significantly decreased by using exfoliated graphene instead of graphene oxide. ${ }^{244}$ Interestingly, Yang et al. have reported the long term effects of PEGylated nano-GO in mice, where no noticeable side effects were observed after 3 months in the organs tested, which included the lungs. ${ }^{245}$ These results seem to show that toxicity of graphene-based materials is localized to lung tissue.

Other in vivo studies have been conducted using chordates, ${ }^{246}$ nematodes ${ }^{247}$ and plants. ${ }^{248}$ In a bio imaging study using functionalized graphene, Gollavelli and Ling noted negligible in vivo toxicity in zebra fish. ${ }^{246}$ Zanni et al. showed similar non-toxic results in their study of graphene-nanoplate distribution in Caenorhabditis elegans. ${ }^{247}$ While graphene seems to not display toxicity in non-mammals, it seems to be highly toxic to plants as has been demonstrated by Begum and coworkers. ${ }^{248}$ In this study the authors concluded that graphene can significantly inhibit plant growth and lead to a reduction in biomass, however it should be noted that extremely high graphene oxide concentration was used in this study $>500 \mathrm{mg} \mathrm{L}^{-1}$.

\section{Outlook}

The discovery of graphene is rightly regarded as a milestone in the world of materials science, as can be seen from the worldwide attention the material has received in the fields of electronics/spintronics, ${ }^{252,253}$ organo electronics, ${ }^{254-257}$ photonics, ${ }^{258}$ supercapacitors, ${ }^{259,260}$ and biosensing ${ }^{261-264}$ to name a few. Research shows that single layer, multilayer and functionalized graphene sheets, as well as other graphene-based architectures offer a wide range of benefits for different applications. The high stability, large surface area and environmentally friendly nature of graphene makes it a potential candidate for environmental applications such as water purification, toxic gas sensors and acidic gas capture, as has been demonstrated in this review article.

The toxicity of graphene-based materials remains to be determined, with various studies showing different results which seem to be related to concentration, tissue type, homogeneity of the material, etc. However, it seems that at low concentrations the toxic effects of graphene can be circumvented, which is very promising if graphene is to be applied in environmental applications.

The graphene sheets prepared via mechanical exfoliation using the scotch tape method are exciting for device fabrication but not appropriate for large scale commercial production, ${ }^{4}$ luckily this problem has largely been overcome with large scale CVD graphene processes. ${ }^{265-267}$ The chemical routes used in the formation of graphene (i.e. GO and rGO) offer large scale production in a cost effective way, however most methods employ toxic/harmful chemicals. ${ }^{268-270}$ The use of graphene and its composites at large scale and low cost in an environmentally friendly way is challenging. It is these challenges that scientists have to rise up to meet so that graphene can eventually be used on an industrial scale and in environmental applications.

\section{Acknowledgements}

This work was supported by NRF (National Honor Scientist Program: 2010-0020414, WCU: R32-2008-000-10180-0).

\section{References}

1 J. Tollefson and N. Gilbert, Nature, 2012, 486, 20.

2 J. D. Shakun, P. U. Clark, F. He, S. A. Marcott, A. C. Mix, Z. Liu, B. Otto-Bliesner, A. Schmittner and E. Bard, Nature, 2012, 484, 49.

3 M. J. La Guardia, R. C. Hale, E. Harvey and D. Chen, Environ. Sci. Technol., 2010, 44, 4658.

4 K. S. Novoselov, A. K. Geim, S. V. Morozov, D. Jiang, Y. Zhang, S. V. Dubonos, I. V. Grigorieva and A. A. Firsov, Science, 2004, 306, 666. 
5 The rise and rise of graphene, Nat. Nanotechnol., 2010, 5, 755.

6 Y. Li, W. Zhou, H. Wang, L. Xie, Y. Liang, F. Wei, J.-C. Idrobo, S. J. Pennycook and H. Dai, Nat. Nanotechnol., 2012, 7, 394.

7 S. K. Min, W. Y. Kim, Y. Cho and K. S. Kim, Nat. Nanotechnol., 2011, 6, 162.

8 J. M. Yuk, J. Park, P. Ercius, K. Kim, D. J. Hellebusch, M. F. Crommie, J. Y. Lee, A. Zettl and A. P. Alivisatos, Science, 2012, 336, 61.

9 F. Schwierz, Nat. Nanotechnol., 2010, 5, 487.

10 S. Myung, J. Park, H. Lee, K. S. Kim and S. Hong, Adv. Mater., 2010, 22, 2045.

11 G.-X. Ni, Y. Zheng, S. Bae, C. Y. Tan, O. Kahya, J. Wu, B. H. Hong, K. Yao and B. Özyilmaz, ACS Nano, 2012, 6, 3935.

12 W. H. Lee, J. Park, S. H. Sim, S. Lim, K. S. Kim, B. H. Hong and K. Cho, J. Am. Chem. Soc., 2011, 133, 4447.

13 S. Y. Park, J. Park, S. H. Sim, M. G. Sung, K. S. Kim, B. H. Hong and S. H. Hong, Adv. Mater., 2011, 23, H263.

14 D. Cohen-Tanugi and J. C. Grossman, Nano Lett., 2012, 12, 3602 .

15 V. Georgakilas, M. Otyepka, A. B. Bourlinos, V. Chandra, N. Kim, K. C. Kemp, P. Hobza, R. Zboril and K. S. Kim, Chem. Rev., 2012, 112, 6156.

16 M. J. Allen, V. C. Tung and R. B. Kaner, Chem. Rev., 2010, 110, 132.

17 S. Park and R. S. Ruoff, Nat. Nanotechnol., 2009, 4, 217.

18 X. Huang, Z. Zeng, Z. Fan, J. Liu and H. Zhang, Adv. Mater., 2012, 24, 5979.

19 Q. Xiang, J. Yu and M. Jaroniec, Chem. Soc. Rev., 2012, 41, 782.

20 Y. Liu, X. Dong and P. Chen, Chem. Soc. Rev., 2012, 41, 2283.

21 W. Choi, I. Lahiri, R. Seelaboyina and Y. S. Kang, Crit. Rev. Solid State Mater. Sci., 2010, 35, 52.

22 M. A. Shannon, P. W. Bohn, M. Elimelech, J. G. Georgiadis, B. J. Mariñas and A. M. Mayes, Nature, 2008, 452, 301.

23 S. P. Dubey, K. Gopal and J. L. Bersillon, J. Environ. Biol., 2009, 30, 327.

24 A. Dabrowski, Adv. Colloid Interface Sci., 2001, 93, 135.

25 R. P. Bansal and M. Goyal, in Activated Carbon Adsorption, CRC Press, FL, USA, 2005, pp. 297-436

26 V. K. K. Upadhyayula, J. P. Ruparelia and A. Agrawal, in Nanoscale Multifunctional Materials: Science and Applications, ed. S. M. Mukhopadhyay, John Wiley \& Sons, Inc., Hoboken, NJ, USA, 2011, ch. 11.

27 T. S. Sreeprasad, S. M. Maliyekkal, K. P. Lisha and T. Pradeep, J. Hazard. Mater., 2011, 186, 921.

28 B. Li, H. Cao and G. Yin, J. Mater. Chem., 2011, 21, 13765.

29 B. Li, H. Cao, J. Yin, Y. A. Wub and J. H. Warner, J. Mater. Chem., 2012, 22, 1876.

30 S. M. Maliyekkal, T. S. Sreeprasad, D. Krishnan, S. Kouser, A. K. Mishra, U. V. Waghmare and T. Pradeep, Small, 2013, 9, 273.

31 S. S. Gupta, T. S. Sreeprasad, S. M. Maliyekkal, S. K. Das and T. Pradeep, ACS Appl. Mater. Interfaces, 2012, 4, 4156.
32 Z. Niu, J. Chen, H. H. Hng, J. Ma and X. Chen, Adv. Mater., 2012, 24, 4144.

33 C. Wang, C. Feng, Y. Gao, X. Ma, Q. Wu and Z. Wang, Chem. Eng. J., 2011, 173, 92.

34 F. Liu, S. Chung, G. Oh and T. S. Seo, ACS Appl. Mater. Interfaces, 2012, 4, 922.

35 T. S. Sreeprasad, S. S. Gupta, S. M. Maliyekkal and T. Pradeep, J. Hazard. Mater., 2013, 246, 213.

36 V. Chandra, J. Park, Y. Chun, J. W. Lee, I.-C. Hwang and K. S. Kim, ACS Nano, 2010, 4, 3979.

37 K. Zhang, V. Dwivedi, C. Chi and J. Wu, J. Hazard. Mater., 2010, 182, 162.

38 J. Zhu, R. Sadu, S. Wei, D. H. Chen, N. Haldolaarachchige, Z. Luo, J. A. Gomes, D. Young and Z. Guoa, ECS J. Solid State Sci. Technol., 2012, 1, M1.

39 X. Luo, C. Wang, S. Luo, R. Dong, X. Tu and G. Zeng, Chem. Eng. J., 2012, 187, 45.

40 H. Jabeen, V. Chandra, S. Jung, J. W. Lee, K. S. Kim and S. B. Kim, Nanoscale, 2011, 3, 3583.

41 J. Zhu, S. Wei, H. Gu, S. B. Rapole, Q. Wang, Z. Luo, N. Haldolaarachchige, D. P. Young and Z. Guo, Environ. Sci. Technol., 2012, 46, 977.

42 H.-P. Cong, X.-C. Ren, P. Wang and S.-H. Yu, ACS Nano, 2012, 6, 2693.

43 Y. Lee and J. Yang, J. Ind. Eng. Chem., 2012, 18, 1178.

44 V. Chandra and K. S. Kim, Chem. Commun., 2011, 47, 3942.

45 S. Li, X. Lu, Y. Xue, J. Lei, T. Zheng and C. Wang, PLoS One, 2012, 7, e43328.

46 N. Zhang, H. Qiu, Y. Si, W. Wang and J. Gao, Carbon, 2011, 49, 827.

47 L. Fan, C. Luo, M. Sun and H. Qiu, J. Mater. Chem., 2012, 22, 24577.

48 C. J. Madadrang, H. Y. Kim, G. Gao, N. Wang, J. Zhu, H. Feng, M. Gorring, M. L. Kasner and S. Hou, ACS Appl. Mater. Interfaces, 2012, 4, 1186.

49 S.-T. Yang, Y. Chang, H. Wang, G. Liu, S. Chen, Y. Wang, Y. Liu and A. Cao, J. Colloid Interface Sci., 2010, 351, 122.

50 G. Zhao, X. Ren, X. Gao, X. Tan, J. Li, C. Chen, Y. Huang and X. Wang, Dalton Trans., 2011, 40, 10945.

51 Z.-H. Huang, X. Zheng, W. Lv, M. Wang, Q.-H. Yang and F. Kang, Langmuir, 2011, 27, 7558.

52 G. Zhao, J. Li, X. Ren, C. Chen and X. Wang, Environ. Sci. Technol., 2011, 45, 10454.

53 Z. Li, F. Chen, L. Yuan, Y. Liu, Y. Zhao, Z. Chai and W. Shi, Chem. Eng. J., 2012, 210, 539.

54 G. Zhao, T. Wen, X. Yang, S. Yang, J. Liao, J. Hu, D. Shao and X. Wang, Dalton Trans., 2012, 41, 6182.

55 Z. Sui, Q. Meng, X. Zhang, R. Ma and B. Cao, J. Mater. Chem., 2012, 22, 8767.

56 S. Vasudevan and J. Lakshmi, RSC Adv., 2012, 2, 5234.

57 Y. Li, P. Zhang, Q. Du, X. Peng, T. Liu, Z. Wang, Y. Xia, W. Zhang, K. Wang, H. Zhu and D. Wu, J. Colloid Interface Sci., 2011, 363, 348.

$58 \mathrm{~J} . \mathrm{Xu}, \mathrm{L}$. Wang and Y. Zhu, Langmuir, 2012, 28, 8418.

59 L. Fan, C. Luo, X. Li, F. Lu, H. Qiu and M. Sun, J. Hazard. Mater., 2012, 215, 272. 
60 S. Li, Z. Niu, X. Zhong, H. Yang, Y. Lei, F. Zhang, W. Hu, Z. Dong, J. Jin and J. Ma, J. Hazard. Mater., 2012, 230, 42.

61 B. Li, H. Cao, G. Yin, Y. Lu and J. Yin, J. Mater. Chem., 2011, 21, 10645.

62 J. Liu, H. Cao, J. Xiong and Z. Cheng, CrystEngComm, 2012, 14, 5140.

63 D. D. Nguyen, N.-H. Tai, S.-B. Lee and W.-S. Kuo, Energy Environ. Sci., 2012, 5, 7908.

64 X. Dong, J. Chen, Y. Ma, J. Wang, M. B. Chan-Park, X. Liu, L. Wang, W. Huang and P. Chen, Chem. Commun., 2012, 48, 10660.

65 M. Zhang, B. Gao, Y. Yao, Y. Xue and M. Inyang, Sci. Total Environ., 2012, 435, 567.

66 T.-D. Nguyen-Phan, V. H. Pham, E. J. Kim, E.-S. Oh, S. H. Hur, J. S. Chung, B. Lee and E. W. Shin, Appl. Surf. Sci., 2012, 258, 4551.

67 T.-D. Nguyen-Phan, E. W. Shin, V. H. Pham, H. Kweon, S. Kim, E. J. Kim and J. S. Chung, J. Mater. Chem., 2012, 22, 20504.

68 S. Pan and X. Liu, New J. Chem., 2012, 36, 1781.

69 J. N. Tiwari, K. Mahesh, N. H. Le, K. C. Kemp, R. Timilsina, R. N. Tiwari and K. S. Kim, Carbon, 2013, 56, 173.

70 J. Guoa, R. Wang, W. W. Tjiu, J. Pan and T. Liu, J. Hazard. Mater., 2012, 225, 63.

71 H. Sun, L. Cao and L. Lu, Nano Res., 2011, 4, 550.

72 L. Ai, C. Zhang and Z. Chen, J. Hazard. Mater., 2011, 192, 1515.

73 Y. Yao, S. Miao, S. Liu, L. P. Ma, H. Sun and S. Wang, Chem. Eng. J., 2012, 184, 326.

74 X. Yang, C. Chen, J. Li, G. Zhao, X. Ren and X. Wang, RSC Adv., 2012, 2, 8821.

75 S. Wu, Y. Wang, Q. Jia, L. Gu and Y. Sun, Adv. Mater. Res., 2012, 493, 533.

76 S. R. Kim, M. K. Parvez and M. Chhowalla, Chem. Phys. Lett., 2009, 483, 124.

77 X.-F. Zhang and Q. Xi, Carbon, 2011, 49, 3842.

78 S. Wiedmann, H. J. van Elferen, E. V. Kurganova, M. I. Katsnelson, A. J. M. Giesbers, A. Veligura, B. J. van Wees, R. V. Gorbachev, K. S. Novoselov, J. C. Maan and U. Zeitler, Phys. Rev. B: Condens. Matter Mater. Phys., 2011, 84, 115314.

79 F. Wang and K. Zhang, Curr. Appl. Phys., 2012, 12, 346.

80 Y. Zhang and C. Pan, J. Mater. Sci., 2010, 46, 2622.

81 X. Liu, L. Pan, T. Lv, G. Zhu, T. Lu, Z. Sun and C. Sun, RSC Adv., 2011, 1, 1245.

82 K. Zhang, K. C. Kemp and V. Chandra, Mater. Lett., 2012, 81, 127.

83 X. Liu, L. Pan, T. Lv, T. Lu, G. Zhu, Z. Sun and C. Sun, Catal. Sci. Technol., 2011, 1, 1189.

84 X. Liu, L. Pan, Q. Zhao, T. Lv, G. Zhu, T. Chen, T. Lu, Z. Sun and C. Sun, Chem.-Eur. J., 2012, 183, 238.

85 X. Liu, L. Pan, T. Lv, G. Zhu, Z. Sun and C. Sun, Chem. Commun., 2011, 47, 11984.

86 H. Ma, J. Shen, M. Shi, X. Lu, Z. Li, Y. Long, N. Li and M. Ye, Appl. Catal., B, 2012, 121, 198.

87 B. Neppolian, A. Bruno, C. L. Bianchi and M. Ashokkumar, Ultrason. Sonochem., 2012, 19, 9.
88 X. An, J. C. Yu, F. Wang, C. Li and Y. Li, Appl. Catal., B, 2013, 129, 80.

89 J. Liu, H. Bai, Y. Wang, Z. Liu, X. Zhang and D. D. Sun, Adv. Funct. Mater., 2010, 20, 4175.

90 L. Ren, X. Qi, Y. Liu, Z. Huang, X. Wei, J. Li, L. Yang and J. Zhong, J. Mater. Chem., 2012, 22, 11765.

91 J. Du, X. Lai, N. Yang, J. Zhai, D. Kisailus, F. Su, D. Wang and L. Jiang, ACS Nano, 2011, 5, 590.

92 K. Gopalakrishnan, H. M. Joshi, P. Kumar, L. S. Panchakarla and C. N. R. Rao, Chem. Phys. Lett., 2011, 511, 304.

93 H. Seema, K. C. Kemp, V. Chandra and K. S. Kim, Nanotechnology, 2012, 23, 355705.

94 J. Zhang, Z. Xiong and X. S. Zhao, J. Mater. Chem., 2011, 21, 3634.

95 T. Lv, L. Pan, X. Liu, T. Lu, G. Zhu and Z. Sun, J. Alloys Compd., 2011, 509, 10086.

96 Y. Yang, L. Ren, C. Zhang, S. Huang and T. Liu, ACS Appl. Mater. Interfaces, 2011, 3, 2779.

97 T. Xu, L. Zhang, H. Cheng and Y. Zhu, Appl. Catal., B, 2011, 101, 382 .

98 S. Liu, J. Tian, L. Wang, Y. Luo and X. Sun, Catal. Sci. Technol., 2012, 2, 339.

99 E. Gao, W. Wang, M. Shang and J. Xu, Phys. Chem. Chem. Phys., 2011, 13, 2887.

100 H. Hu, X. Wang, F. Liu, J. Wang and C. Xu, Synth. Met., 2011, 161, 404.

101 P. Chen, T.-Y. Xiao, H.-H. Li, J.-J. Yang, Z. Wang, H.-B. Yao and S.-H. Yu, ACS Nano, 2012, 6, 712.

102 Z. Xiong, L. L. Zhang and X. S. Zhao, Chem.-Eur. J., 2011, 17, 2428.

103 Z. Xiong, L. L. Zhang, J. Ma and X. S. Zhao, Chem. Commun., 2010, 46, 6099.

104 M. Zhu, P. Chen and M. Liu, ACS Nano, 2011, 5, 4529.

105 G. Z. Liao, S. Chen, X. Quan, H. T. Yu and H. M. Zhao, J. Mater. Chem., 2012, 22, 2721.

106 L. L. Zhang, Z. Xiong and X. S. Zhao, ACS Nano, 2010, 4, 7030.

107 Y. Zhang, Z.-R. Tang, X. Fu and Y.-J. Xu, ACS Nano, 2010, 4, 7303.

108 H. Zhang, X. Lv, Y. Li, Y. Wang and J. Li, ACS Nano, 2010, 4, 380.

109 J. S. Lee, K. H. You and C. B. Park, Adv. Mater., 2012, 24, 1084.

110 Y. H. Ng, I. V. Lightcap, K. Goodwin, M. Matsumura and P. V. Kamat, J. Phys. Chem. Lett., 2010, 1, 2222.

111 Y. Liang, H. Wang, H. S. Casalongue, Z. Chen and H. Dai, Nano Res., 2010, 3, 701.

112 S. D. Perera, R. G. Mariano, K. Vu, N. Nijem, O. Seitz, Y. J. Chabal and J. K. J. Balkus, ACS Catal., 2012, 2, 949.

113 D. L. Zhao, G. D. Sheng, C. L. Chen and X. K. Wang, Appl. Catal., B, 2012, 111, 303.

114 R. Zou, Z. Zhang, L. Yu, Q. Tian, Z. Chen and J. Hu, Chem.Eur. J., 2011, 17, 13912.

115 T. Kamegawa, D. Yamahana and H. Yamashita, J. Phys. Chem. C, 2010, 114, 15049.

116 Y. Wen, H. Ding and Y. Shan, Nanoscale, 2011, 3, 4411. 
117 Q.-P. Luo, X.-Y. Yu, B.-X. Lei, H.-Y. Chen, D.-B. Kuang and C.-Y. Su, J. Phys. Chem. C, 2012, 116, 8111.

118 X. An, J. C. Yu, Y. Wang, Y. Hu, X. Yu and G. Zhang, J. Mater. Chem., 2012, 22, 8525.

119 X. Wang, H. Tian, Y. Yang, H. Wang, W. Zheng and Y. Liu, J. Alloys Compd., 2012, 524, 5.

120 A. Ye, W. Fan, Q. Zhang, W. Deng and Y. Wang, Catal. Sci. Technol., 2012, 2, 969.

121 Y. Fu and X. Wang, Ind. Eng. Chem. Res., 2011, 50, 7210.

122 Y. Fu, P. Xiong, H. Chen, X. Sun and X. Wang, Ind. Eng. Chem. Res., 2012, 51, 725.

123 Y. Fu, H. Chen, X. Sun and X. Wang, AIChE J., 2012, 58, 3298.

124 S. Bai, X. Shen, X. Zhong, Y. Liu, G. Zhu, X. Xu and K. Chen, Carbon, 2012, 50, 2337.

125 Y.-L. Min, K. Zhang, Y.-C. Chen and Y.-G. Zhang, Sep. Purif. Technol., 2012, 86, 98.

126 F. Zhou, R. Shi and Y. Zhu, J. Mol. Catal. A: Chem., 2011, 340, 77.

127 X. Zhang, X. Quan, S. Chen and H. Yu, Appl. Catal., B, 2011, $105,237$.

128 H. Zhang, X. Fan, X. Quan, S. Chen and H. Yu, Environ. Sci. Technol., 2011, 45, 5731.

129 T.-D. Nguyen-Phan, V. H. Pham, E. W. Shin, H.-D. Pham, S. Kim, J. S. Chung, E. J. Kim and S. H. Hur, Chem.-Eur. J., 2011, 170, 226.

130 J. Liu, L. Liu, H. Bai, Y. Wang and D. D. Sun, Appl. Catal., B, 2011, 106, 76.

131 G. Jiang, Z. Lin, C. Chen, L. Zhu, Q. Chang, N. Wang, W. Wei and H. Tang, Carbon, 2011, 49, 2693.

132 W. C. Lee, C. Haley, Y. X. Lim, H. Shi, L. A. L. Tang, Y. Wang, C. T. Lim and K. P. Loh, ACS Nano, 2011, 5, 7334.

133 W. Hu, C. Peng, W. Luo, M. Lv, X. Li, D. Li, Q. Huang and C. Fan, ACS Nano, 2010, 4, 4317.

134 O. Akhavan and E. Ghaderi, J. Phys. Chem. C, 2009, 113, 20214.

135 O. Akhavan, M. Choobtashani and E. Ghaderi, J. Phys. Chem. C, 2012, 116, 9653.

136 L. Liu, J. Liu and D. D. Sun, Catal. Sci. Technol., 2012, 2, 2525.

137 T. S. Sreeprasad, M. S. Maliyekkal, K. Deepti, K. Chaudhari, P. L. Xavier and T. Pradeep, ACS Appl. Mater. Interfaces, 2011, 3, 2643.

138 X. Cai, S. Tan, M. Lin, A. Xie, W. Mai, X. Zhang, Z. Lin, T. Wu and Y. Liu, Langmuir, 2011, 27, 7828.

139 P. Cox and C. Jones, Science, 2008, 321, 1642.

140 J. P. Smol, Nature, 2012, 483, S12.

141 K. J. van Groenigen, C. W. Osenberg and B. A. Hungate, Nature, 2011, 475, 214.

142 D. M. D'Alessandro, B. Smit and J. R. Long, Angew. Chem., Int. Ed., 2010, 49, 6058.

143 L. Schlapbach and A. Züttel, Nature, 2001, 414, 353.

144 D. Y. Kim, H. M. Lee, S. K. Min, Y. Cho, I.-C. Hwang, K. Han, J. Y. Kim and K. S. Kim, J. Phys. Chem. Lett., 2011, 2, 689.

145 A. K. Mishra and S. Ramaprabhu, AIP Adv., 2011, 1, 032152.
146 V. Chandra, S. U. Yu, S. H. Kim, Y. S. Yoon, D. Y. Kim, A. H. Kwon, M. Meyyappan and K. S. Kim, Chem. Commun., 2012, 48, 735.

147 A. K. Mishra and S. Ramaprabhu, J. Mater. Chem., 2012, 22, 3708.

148 G. Srinivas and T. Yildirim, Energy Environ. Sci., 2012, 5, 6453.

149 G. Ning and F. Wei, Chem. Commun., 2012, 48, 6815.

150 A. G. Gallastegui, D. Iruretagoyena, V. Gouvea, M. Mokhtar, A. M. Asiri, S. N. Basahel, S. A. Al-Thabaiti, A. O. Alyoubi, D. Chadwick and M. S. P. Shaffer, Chem. Mater., 2012, 24, 4531.

151 B. C. Wood and A. D. Pathak, J. Chem. Phys., 2012, 137, 054702.

152 M. Shan, Q. Xue, N. Jing, C. Ling, T. Zhang, Z. Yan and J. Zheng, Nanoscale, 2012, 4, 5477.

153 I. Carrillo, E. Rangel and L. F. Magana, Carbon, 2009, 47, 2758.

154 C. Cazorla, S. A. Shevlin and Z. X. Guo, J. Phys. Chem. C, 2011, 115, 10990.

155 G. Srinivas, Y. Zhu, R. Piner, N. Skipper, M. Ellerby and R. Ruoff, Carbon, 2010, 48, 630.

156 C. X. Guo, Y. Wang and C. M. Li, ACS Sustainable Chem. Eng., 2013, 1, 14.

157 N. Park, S. Hong, G. Kim and S. H. Jhi, J. Am. Chem. Soc., 2007, 129, 8999.

158 W. Liu, Y. H. Zhao, J. Nguyen, Y. Li, Q. Jiang and E. J. Lavernia, Carbon, 2009, 47, 3452.

159 V. Tozzini and V. Pellegrini, J. Phys. Chem. C, 2011, 115, 25523.

160 D. Y. Kim, H. M. Lee, J. Seo, S. K. Shin and K. S. Kim, Phys. Chem. Chem. Phys., 2010, 12, 5446.

161 D. Y. Kim, N. J. Singh, H. M. Lee and K. S. Kim, Chem.-Eur. J., 2009, 15, 5598.

162 H. M. Lee, D. Y. Kim, C. Pak, N. J. Singh and K. S. Kim, J. Chem. Theory Comput., 2011, 7, 969.

163 L. Wang, K. Lee, Y. Y. Sun, M. Lucking, Z. Chen, J. J. Zhao and S. B. Zhang, ACS Nano, 2009, 3, 2995.

164 H. Lee, J. Ihm, M. L. Cohen and S. G. Louie, Nano Lett., 2010, 10, 793.

165 T. Hussain, B. Pathak, M. Ramzan, T. A. Maark and R. Ahuja, Appl. Phys. Lett., 2012, 100, 183902.

166 C. Ataca, E. Aktürk, S. Ciraci and H. Ustunel, Appl. Phys. Lett., 2008, 93, 043123.

167 A. Du, Z. Zhu and S. C. Smith, J. Am. Chem. Soc., 2010, 132, 2876.

168 S. Patchkovskii, J. S. Tse, S. N. Yurchenko, L. Zhechkov, T. Heine and G. Seifert, Proc. Natl. Acad. Sci. U. S. A., 2005, 102, 10439.

169 B. H. Kim, W. G. Hong, H. Y. Yu, Y. K. Han, S. M. Lee, S. J. Chang, H. R. Moon, Y. Jun and H. J. Kim, Phys. Chem. Chem. Phys., 2012, 14, 1480.

170 J. W. Burress, S. Gadipelli, J. Ford, J. M. Simmons, W. Zhou and T. Yildirim, Angew. Chem., Int. Ed., 2010, 49, 8902.

171 Y. Chan and J. M. Hill, Nanotechnology, 2011, 22, 305403.

172 G. Srinivas, J. W. Burress, J. Forda and T. Yildirim, J. Mater. Chem., 2011, 21, 11323. 
173 G. K. Dimitrakakis, E. Tylianakis and G. E. Froudakis, Nano Lett., 2008, 8, 3166.

174 E. Tylianakis, G. M. Psofogiannakis and G. E. Froudakis, J. Phys. Chem. Lett., 2010, 1, 2459.

175 S. H. Aboutalebi, S. A. Yamini, I. Nevirkovets, K. Konstantinov and H. K. Liu, Adv. Energy Mater., 2012, 2, 1439.

176 S. Tang and Z. Cao, J. Chem. Phys., 2011, 134, 044710.

177 M. Seredych and T. J. Bandosz, Langmuir, 2010, 26, 5491.

178 M. Seredych, A. V. Tamashausky and T. J. Bandosz, Adv. Funct. Mater., 2010, 20, 1670.

179 M. Seredych, J. A. Rossin and T. J. Bandosz, Carbon, 2011, 49, 4392.

180 P. Solís-Fernández, R. Rozada, J. I. Paredes, S. Villar-Rodil, M. J. Fernández-Merino, L. Guardia, A. Martínez-Alonso and J. M. D. Tascón, J. Alloys Compd., 2012, 536, S532.

181 F. Liu, W. Chu, W. Sun, Y. Xue and Q. Jiang, J. Nat. Gas Chem., 2012, 21, 708.

182 L. Wang and S. B. Zhang, Phys. Chem. Chem. Phys., 2011, 13, 21126.

183 M. Seredych and T. J. Bandosz, Mater. Chem. Phys., 2009, 117, 99.

184 M. Seredych and T. J. Bandosz, Colloids Surf., A, 2010, 353, 30.

185 M. Seredych and T. J. Bandosz, Microporous Mesoporous Mater., 2012, 150, 55.

186 C. Petit and T. J. Bandosz, Adv. Funct. Mater., 2010, 20, 111. 187 T. J. Bandosz and C. Petit, Adsorption, 2011, 17, 5.

188 C. Petit, S. Wrabetz and T. J. Bandosz, J. Mater. Chem., 2012, 22, 21443.

189 C. Petit and T. J. Bandosz, Adv. Funct. Mater., 2011, 21, 2108.

190 M. Seredych and T. J. Bandosz, Mater. Chem. Phys., 2009, 113, 946.

191 M. Seredych, O. Mabayoje and T. J. Bandosz, Langmuir, 2012, 28, 1337.

192 M. Seredych and T. J. Bandosz, Chem. Eng. J., 2011, 166, 1032.

193 O. Mabayoje, M. Seredych and T. J. Bandosz, J. Colloid Interface Sci., 2012, 378, 1.

194 O. Mabayoje, M. Seredych and T. J. Bandosz, ACS Appl. Mater. Interfaces, 2012, 4, 3316.

195 A. Petit, B. Mendoza and T. J. Bandosz, ChemPhysChem, 2010, 11, 3678.

196 A. Petit, B. Levasseur, B. Mendoza and T. J. Bandosz, Microporous Mesoporous Mater., 2012, 154, 107.

197 C. Petit and T. J. Bandosz, Dalton Trans., 2012, 41, 4027.

198 S. Bashkova and T. J. Bandosz, Ind. Eng. Chem. Res., 2009, 48, 10884.

199 B. Levasseur, C. Petit and T. J. Bandosz, ACS Appl. Mater. Interfaces, 2010, 2, 3606.

200 M. Seredych and T. J. Bandosz, J. Phys. Chem. C, 2010, 114, 14552.

201 X. Sha, M. T. Knippenberg, A. C. Cooper, G. P. Pez and H. Cheng, J. Phys. Chem. C, 2008, 112, 17465.

202 A. K. Singh, M. A. Ribas and B. I. Yakobson, ACS Nano, 2009, 3, 1657.
203 H. Y. Wu, X. Fan, J. L. Kuo and W. Q. Deng, J. Phys. Chem. C, 2011, 115, 9241.

204 V. B. Parambhath, R. Nagar, K. Sethupathi and S. Ramaprabhu, J. Phys. Chem. C, 2011, 115, 15679.

205 C.-C. Huang, N.-W. Pu, C.-A. Wang, J.-C. Huang, Y. Sung and M.-D. Ger, Sep. Purif. Technol., 2011, 82, 210.

206 Y. Wang, J. Liu, K. Wang, T. Chen, X. Tan and C. M. Li, Int. J. Hydrogen Energy, 2011, 36, 12950.

207 Y. Wang, C. X. Guo, X. Wang, C. Guan, H. Yang, K. Wanga and C. M. Li, Energy Environ. Sci., 2011, 4, 195.

208 P. Bernardo, E. Drioli and G. Golemme, Ind. Eng. Chem. Res., 2009, 48, 4638.

209 J. C. Meyer, A. K. Geim, M. I. Katsnelson, K. S. Novoselov, T. J. Booth and S. Roth, Nature, 2007, 446, 60.

210 C. Lee, X. Wei, J. W. Kysar and J. Hone, Science, 2008, 321, 385.

211 J. S. Bunch, S. S. Verbridge, J. S. Alden, A. M. van der Zande, J. M. Parpia, H. G. Craighead and P. L. McEuen, Nano Lett., 2008, 8, 2458.

212 R. R. Nair, H. A. Wu, P. N. Jayaram, I. V. Grigorieva and A. K. Geim, Science, 2012, 335, 442.

213 O. Leenaerts, B. Partoens and F. M. Peeters, Appl. Phys. Lett., 2008, 93, 193107.

214 M. D. Fischbein and M. Drndic, Appl. Phys. Lett., 2008, 93, 113107.

215 D. E. Jiang, V. R. Cooper and S. Dai, Nano Lett., 2009, 9, 4019.

216 H. Du, J. Li, J. Zhang, G. Su, X. Li and Y. Zhao, J. Phys. Chem. $C, 2011,115,23261$.

217 S. P. Koenig, L. Wang, J. Pellegrino and J. S. Bunch, Nat. Nanotechnol., 2012, 7, 728.

218 S. Blankenburg, M. Bieri, R. Fasel, K. Müllen, C. A. Pignedoli and D. Passerone, Small, 2010, 6, 2266.

219 M. Hankel, Y. Jiao, A. Du, S. K. Gray and S. C. Smith, J. Phys. Chem. C, 2012, 116, 6672.

220 A. W. Hauser and P. Schwerdtfeger, J. Phys. Chem. Lett., 2012, 3, 209.

221 A. W. Hauser and P. Schwerdtfeger, Phys. Chem. Chem. Phys., 2012, 14, 13292.

222 X. Qin, Q. Meng, Y. Feng and Y. Gao, Surf. Sci., 2013, 607, 153.

223 J. Schrier, J. Phys. Chem. Lett., 2010, 1, 2284.

224 J. Schrier, ACS Appl. Mater. Interfaces, 2011, 3, 4451.

225 M. Bieri, M. Trier, J. Cai, K. Aït-Mansour, P. Ruffieux, O. Gröning, P. Gröning, M. Kastler, R. Rieger, X. Feng, K. Müllen and R. Fasel, Chem. Commun., 2009, 6919.

226 J.-J. Chen, W.-W. Li, X.-L. Li and H.-Q. Yu, Environ. Sci. Technol., 2012, 46, 10341.

227 A. M. Brockway and J. Schrier, J. Phys. Chem. C, 2013, 117, 393.

228 O. N. Ruiz, K. A. Fernando, B. Wang, N. A. Brown, P. G. Luo, N. D. McNamara, M. Vangsness, Y. P. Sun and C. E. Bunker, ACS Nano, 2011, 5, 8100.

229 K. H. Liao, Y. S. Lin, C. W. Macosko and C. L. Haynes, ACS Appl. Mater. Interfaces, 2011, 3, 2607.

230 N. Li, X. Zhang, Q. Song, R. Su, Z. Qi, T. Kong, L. Liu, G. Jin, M. Tang and G. Cheng, Biomaterials, 2011, 32, 9374. 
231 W. C. Lee, C. H. Y. X. Lim, H. Shi, L. A. L. Tang, Y. Wang,

C. T. Lim and K. P. Loh, ACS Nano, 2011, 5, 7334.

232 O. Akhavan and E. Ghaderi, ACS Nano, 2010, 4, 573.

233 S. Liu, T. H. Zeng, M. Hofmann, E. Burcombe, J. Wei, R. Jiang, J. Kong and Y. Chen, ACS Nano, 2011, 5, 6971.

234 Y. Chang, S. T. Yang, J. H. Liu, E. Dong, Y. Wang, A. Cao, Y. Liu and H. Wang, Toxicol. Lett., 2011, 200, 201.

235 W. Hu, C. Peng, M. Lv, X. Li, Y. Zhang, N. Chen, C. Fan and Q. Huang, ACS Nano, 2011, 5, 3693.

236 G. Gollavelli and Y. C. Ling, Biomaterials, 2012, 33, 2532.

237 L. Feng, S. Zhang and Z. Liu, Nanoscale, 2011, 3, 1252.

238 J. T. Robinson, S. M. Tabakman, Y. Liang, H. Wang, H. S. Casalongue, D. Vinh and H. Dai, J. Am. Chem. Soc., 2011, 133, 6825.

239 S. Agarwal, X. Zhou, F. Ye, Q. He, G. C. Chen, J. Soo, F. Boey, H. Zhang and P. Chen, Langmuir, 2010, 26, 2244.

240 Y. Zhang, S. F. Ali, E. Dervishi, Y. Xu, Z. Li, D. Casciano and A. S. Biris, ACS Nano, 2010, 4, 3181.

241 C.-W. Lam, J. T. James, R. McCluskey and R. L. Hunter, Toxicol. Sci., 2004, 77, 126.

242 L. Yan, F. Zhao, S. Li, Z. Hu and Y. Zhao, Nanoscale, 2011, 3, 362.

243 X. Zhan, J. L. Yin, C. Peng, W. Hu, Z. Zhu, W. Li, C. Fan and Q. Huang, Carbon, 2011, 49, 986.

244 M. C. Duch, G. R. Budinger, Y. T. Liang, S. Soberanes, D. Urich, S. E. Chiarella, L. A. Campochiaro, A. Gonzalez, N. S. Chandel, M. C. Hersam and G. M. Mutlu, Nano Lett., 2011, 11, 5201.

245 K. Yang, J. M. Wan, S. A. Zhang, Y. J. Zhang, S. T. Lee and Z. Liu, ACS Nano, 2011, 5, 516.

246 G. Gollavelli and Y. C. Ling, Biomaterials, 2012, 33, 2532.

247 E. Zanni, G. De Bellis, M. P. Bracciale, A. Broggi, M. L. Santarelli, M. S. Sarto, C. Palleschi and D. Uccelletti, Nano Lett., 2012, 12, 2740.

248 P. Begum, R. I. Ikhtiari and B. Fugetsu, Carbon, 2011, 49, 3907.

249 Y. Zhang, G. Mo, X. Li, W. Zhang, J. Zhang, J. Ye, X. Huang and C. Yu, J. Power Sources, 2011, 196, 5402.

250 G. Wang, F. Qian, C. W. Saltikov, Y. Jiao and Y. Li, Nano Res., 2011, 4, 563.

251 O. Akhavan and E. Ghaderia, Carbon, 2012, 50, 1853.

252 J. Park, S. B. Jo, Y.-J. Yu, Y. Kim, J. W. Yang, W. H. Lee, H. H. Kim, B. H. Hong, P. Kim, K. Cho and K. S. Kim, Adv. Mater., 2012, 24, 407.
253 W. Y. Kim and K. S. Kim, Nat. Nanotechnol., 2008, 3, 408. 254 W. H. Lee, J. W. Suk, J. Lee, Y. Hao, J. Park, J. W. Yang, H.-W. Ha, S. Murali, H. Chou, D. Akinwande, K. S. Kim and R. S. Ruoff, ACS Nano, 2012, 6, 1284.

255 S. Huh, J. Park, K. S. Kim, B. H. Hong and S. B. Kim, ACS Nano, 2011, 5, 3639.

256 W. H. Lee, J. Park, Y. Kim, K. S. Kim, B. H. Hong and K. Cho, Adv. Mater., 2011, 23, 3460.

257 W. H. Lee, J. Park, S. H. Sim, S. B. Jo, K. S. Kim, B. H. Hong and K. Cho, Adv. Mater., 2011, 23, 1752.

258 F. Bonaccorso, Z. Sun, T. Hasan and A. C. Ferrari, Nat. Photonics, 2010, 4, 611.

259 M. D. Stoller, S. J. Park, Y. W. Zhu, J. H. An and R. S. Ruoff, Nano Lett., 2008, 8, 3498.

260 M. F. El-Kady, V. Strong, S. Dubin and R. B. Kaner, Science, 2012, 335, 1326.

261 S. Myung, C. Kim, P. T. Yin, J. Park, A. Solanki, P. I. Reyes, Y. Lu, K. S. Kim and K.-B. Lee, Adv. Mater., 2012, 24, 6081.

262 S. Myung, A. Solanki, C. Kim, J. Park, K. S. Kim and K.-B. Lee, Adv. Mater., 2011, 23, 2221.

263 J. W. Yi, J. Park, K. S. Kim and B. H. Kim, Org. Biomol. Chem., 2011, 9, 7434.

264 J. W. Yi, J. Park, N. J. Singh, I. J. Lee, K. S. Kim and B. H. Kim, Bioorg. Med. Chem. Lett., 2011, 21, 704.

265 K. S. Kim, Y. Zhao, H. Jang, S. Y. Lee, J. M. Kim, K. S. Kim, J.-H. Ahn, P. Kim, J.-Y. Choi and B. H. Hong, Nature, 2009, 457, 706.

266 X. Li, W. Cai, J. An, S. Kim, J. Nah, D. Yang, R. Piner, A. Velamakanni, I. Jung, E. Tutuc, S. K. Banerjee, L. Colombo and R. S. Ruoff, Science, 2009, 324, 1312.

267 S. Bae, H. Kim, Y. Lee, X. Xu, J.-S. Park, Y. Zheng, J. Balakrishnan, T. Lei, H. R. Kim, Y. I. Song, Y.-J. Kim, K. S. Kim, B. Ozyilmaz, J.-H. Ahn, B. H. Hong and S. Iijima, Nat. Nanotechnol., 2010, 5, 574.

268 S. Stankovich, D. A. Dikin, R. D. Piner, K. A. Kohlhaas, A. Kleinhammes, Y. Jia, Y. Wu, S. B. T. Nguyen and R. S. Ruoff, Carbon, 2007, 45, 1558.

269 H. J. Shin, K. K. Kim, A. Benayad, S. M. Yoon, H. K. Park, I. S. Jung, M. H. Jin, H. K. Jeong, J. M. Kim, J. Y. Choi and Y. H. Lee, Adv. Funct. Mater., 2009, 19, 1987.

270 S. Pei, J. Zhao, J. Du, W. Ren and H.-M. Cheng, Carbon, 2010, 48, 4466. 